\title{
PLANT MODEL OF KIPT NEUTRON SOURCE FACILITY SIMULATOR
}

Nuclear Engineering Division 


\section{About Argonne National Laboratory}

Argonne is a U.S. Department of Energy laboratory managed by UChicago Argonne, LLC under contract DE-AC02-06CH11357. The Laboratory's main facility is outside Chicago, at 9700 South Cass Avenue, Argonne, Illinois 60439. For information about Argonne and its pioneering science and technology programs, see www.anl.gov.

\section{DOCUMENT AVAILABILITY}

Online Access: U.S. Department of Energy (DOE) reports produced after 1991 and a growing number of pre-1991 documents are available free via DOE's SciTech Connect (http://www.osti.gov/scitech/)

Reports not in digital format may be purchased by the public from the National Technical Information Service (NTIS):

U.S. Department of Commerce

National Technical Information Service

5301 Shawnee Rd

Alexandria, VA 22312

www.ntis.gov

Phone: (800) 553-NTIS (6847) or (703) 605-6000

Fax: (703) 605-6900

Email: orders@ntis.gov

Reports not in digital format are available to DOE and DOE contractors from the Office of Scientific and Technical Information (OSTI):

U.S. Department of Energy

Office of Scientific and Technical Information

P.O. Box 62

Oak Ridge, TN 37831-0062

www.osti.gov

Phone: (865) 576-8401

Fax: (865) 576-5728

Email: reports@osti.gov

\section{Disclaimer}

This report was prepared as an account of work sponsored by an agency of the United States Government. Neither the United States Government nor any agency thereof, nor UChicago Argonne, LLC, nor any of their employees or officers, makes any warranty, express or implied, or assumes any legal liability or responsibility for the accuracy, completeness, or usefulness of any information, apparatus, product, or process disclosed, or represents that its use would not infringe privately owned rights. Reference herein to any specific commercial product, process, or service by trade name, trademark, manufacturer, or otherwise, does not necessarily constitute or imply its endorsement, recommendation, or favoring by the United States Government or any agency thereof. The views and opinions of document authors expressed herein do not necessarily state or reflect those of the United States Government or any agency thereof, Argonne National Laboratory, or UChicago Argonne, LLC. 


\section{PLANT MODEL OF KIPT NEUTRON SOURCE FACILITY SIMULATOR}

By

Yan Cao, Thomas Y. Wei, Austin L. Grelle, and Yousry Gohar

Nuclear Engineering Division, Argonne National Laboratory

February 2016 


\title{
PLANT MODEL OF KIPT NEUTRON SOURCE FACILITY SIMULATOR
}

\author{
$\underline{\text { Table of Contents }}$
}

\begin{abstract}
Page

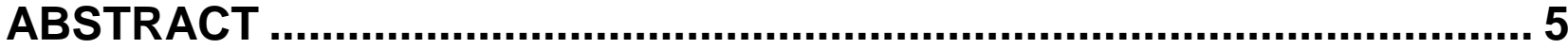

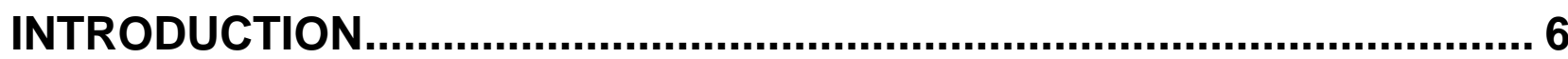

I. PHYSICS MODEL OF THE PLANT COMPONENTS ............................. 7

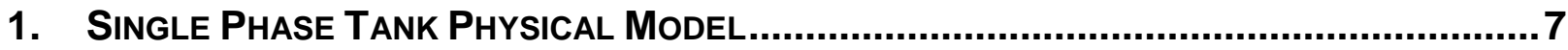

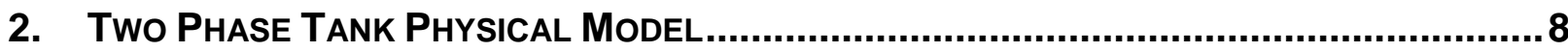

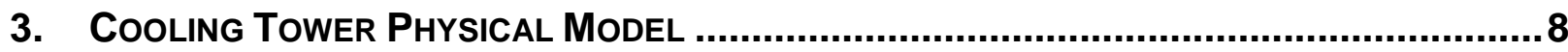

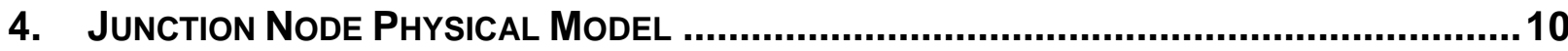

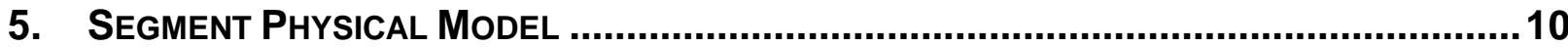

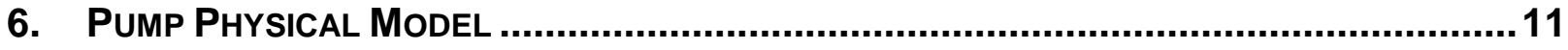

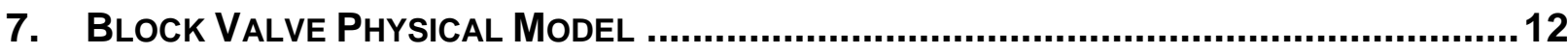

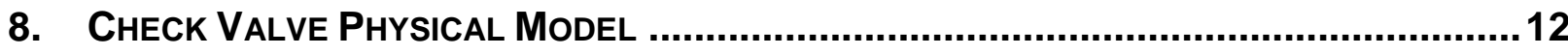

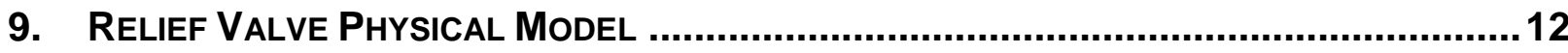

10. Single Phase Heat Exchanger Physical Model ............................................... 13

11. Single-Phase Heat Source Physical Model ...................................................... 14

II. KIPT COOLING SYSTEMS ............................................................. 15

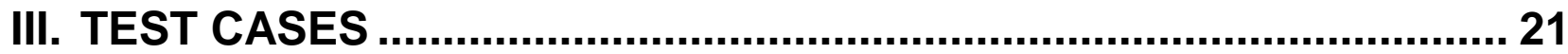

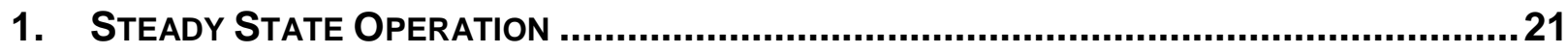

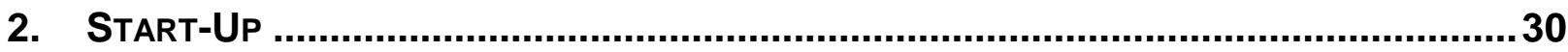

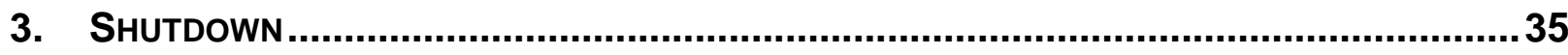

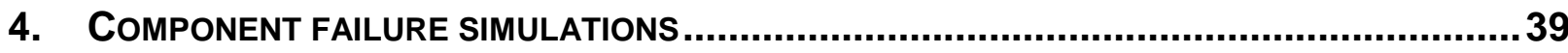

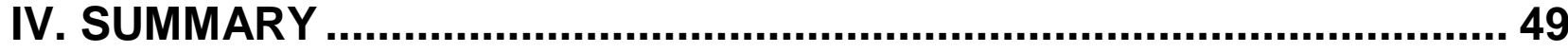

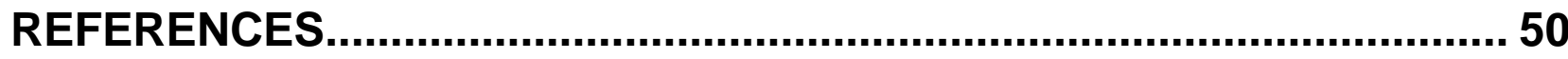

APPENDIX A: COMPONENT CONTROL FUNCTIONS .......................... 51 


\title{
PLANT MODEL OF KIPT NEUTRON SOURCE FACILITY SIMULATOR
}

\author{
List of Figures
}

Page

Figure 1. Schematic representation of the physical model of a single phase tank.

Figure 2. Schematic representation of the physical model of a two phase tank. .........8

Figure 3. Schematic representation of the physical model of a cooling tower. ..........10

Figure 4. Schematic representation of the physics model of a junction node. ........... 10

Figure 5. Schematic representation of the physics model of a segment....................11

Figure 6. Schematic representation of the physical model of a pump. ......................11

Figure 7. Schematic representation of the physical model of a check valve.............. 12

Figure 8. Schematic representation of the physics model of a relief valve. ............... 13

Figure 9. Schematic representation of the physical model of a heat exchanger........13

Figure 10. Schematic representation of the physical model of a heat exchanger

(a) tank after the heat element (b) tank before the heat element.

Figure 11. Plant physical model of the KIPT subcritical assembly primary cooling loop.

Figure 12. Plant model of the KIPT target primary cooling loop

Figure 13. Plant model of the secondary cooling system of the KIPT subcritical assembly and the target primary cooling loops

Figure 14. Plant model of the secondary cooling loop of the KIPT electron accelerator

Figure 15. Calculated pressure, total flow rate, and temperature values of the SCA primary cooling loops with pump $\mathrm{H} 22$ operating at full speed and the KIPT neutron source facility is operating at steady state for $100 \mathrm{~s}$.

Figure 16. Calculated pressure, total flow rate, and temperature values of the target primary cooling loops with pump $\mathrm{H} 2$ operating at full speed and the KIPT neutron source facility is operating at steady state for $100 \mathrm{~s}$

Figure 17. Calculated pressure, total flow rate, and temperature values of the secondary cooling loop coupled of the SCA and target primary loops with pump Z-201/1 and Z-201/2 operating at full speed and the KIPT neutron source facility is operating at steady state for $100 \mathrm{~s}$. 
Figure 18. Calculated pressure, flow rate, and temperature values of the KIPT secondary cooling loops coupled with the accelerator primary systems at steady state with pump Z-202/1 and Z-202/2 operating at full speed and the KIPT neutron source facility is operating at steady state for $100 \mathrm{~s}$.

Figure 19. Calculated pressure, total flow rate, and temperature values of the subcritical assembly primary cooling systems with pump $\mathrm{H} 22$ and $\mathrm{H} 23$ operating at full speed and the KIPT neutron source facility is operating at steady state for $100 \mathrm{~s}$.

Figure 20. Calculated pressure, total flow rate, and temperature values of the target primary cooling systems with pump $\mathrm{H} 2$ and $\mathrm{H} 3$ operating at full speed and the KIPT neutron source facility is operating at steady state for $100 \mathrm{~s}$.

Figure 21. Calculated pressure, total flow rate, and temperature values of the subcritical assembly primary cooling systems with pump $\mathrm{H} 22$ and $\mathrm{H} 23$ operated at half speed and the KIPT neutron source facility is operating at steady state for $100 \mathrm{~s}$.

Figure 22. Calculated pressure, total flow rate, and temperature values of the target primary cooling systems with pump $\mathrm{H} 2$ and $\mathrm{H} 3$ operating at half speed and the KIPT neutron source facility is operating at steady state for $100 \mathrm{~s}$.

Figure 23. Calculated pressure, total flow rates, and temperatures of the SCA primary cooling systems with pump $\mathrm{H} 22$ operating at full speed and the KIPT neutron source facility starts from cold shutdown for $500 \mathrm{~s}$ operating time.

Figure 24. Calculated pressure, total flow rates, and temperatures of the target primary cooling systems with pump $\mathrm{H} 2$ operating at full speed and the KIPT neutron source facility starts from cold shutdown for $500 \mathrm{~s}$ operating time.

Figure 25. Calculated pressure, total flow rates, and temperatures of the secondary cooling system coupled with the subcritical assembly and target primary cooling systems and pump Z-201/1 and Z-201/2 operating at full speed and the KIPT neutron Source facility starts from cold shutdown for $500 \mathrm{~s}$ operating time.

Figure 26. Calculated pressure, total flow rates, and temperatures of the secondary cooling system coupled with the accelerator primary cooling systems and pump Z-202/1 and Z-202/2 operating at full speed and the KIPT neutron source facility starts from cold shutdown for 500 s operating time.

Figure 27. Calculated temperatures of the KIPT neutron source facility starting from cold shutdown for $5000 \mathrm{~s}$ operating time. 
Figure 28. Calculated pressure, flow rates, and temperatures of the subcritical assembly primary cooling loop for the assumed shutdown test case.

Figure 29. Calculated pressure, flow rates, and temperatures of the target primary cooling loop for the assumed shutdown test case.

Figure 30. Calculated pressure, flow rates, and temperatures of the targetsubcritical assembly cooling loop for the assumed shutdown test case.

Figure 31. Calculated pressure, flow rates, and temperatures of the accelerator secondary cooling loop for the assumed shutdown test case.

Figure 32. Calculated sensor temperatures of the KIPT neutron source facility for accelerator trip event.

Figure 33. The calculated transients of the pressure, temperature, and flow rates of the KIPT neutron source facility in the SCA and target primary loop for the SCA pump trip accident.

Figure 33. The calculated temperature transients of the KIPT neutron source facility in the secondary loops for the SCA pump trip accident.

Figure 34. The calculated transients of the pressure, temperature, and flow rates of the KIPT neutron source facility at the target pump trip accident scenario.

Figure 35. The calculated transients of the temperature in the secondary cooling system of the KIPT neutron source facility at the target pump trip accident scenario.

Figure 37. The calculated transients of the pressure, flow rates, and temperature of the KIPT neutron source facility at the secondary cooling system pump trip accident scenario.

Figure 36. The calculated transients of the temperature in the SCA and target primary cooling systems of the KIPT neutron source facility at the secondary cooling system pump trip accident scenario.

Figure 38. The calculated transients of the temperatures of the KIPT neutron source facility at the secondary air blower trip accident scenario. 


\title{
PLANT MODEL OF KIPT NEUTRON SOURCE FACILITY SIMULATOR
}

\begin{abstract}
Argonne National Laboratory (ANL) of the United States and Kharkov Institute of Physics and Technology (KIPT) of Ukraine are collaborating on constructing a neutron source facility at KIPT, Kharkov Ukraine. The facility has 100-kW electron beam driving a subcritical assembly (SCA). The electron beam interacts with a natural uranium target or a tungsten target to generate neutrons, and deposits its power in the target zone. The total fission power generated in SCA is about $300 \mathrm{~kW}$. Two primary cooling loops are designed to remove $100-\mathrm{kW}$ and $300-\mathrm{kW}$ from the target zone and the SCA, respectively. A secondary cooling system is coupled with the primary cooling system to dispose of the generated heat outside the facility buildings to the atmosphere. In addition, the electron accelerator has a low efficiency for generating the electron beam, which uses another secondary cooling loop to remove the generated heat from the accelerator primary cooling loop.

One of the main functions the KIPT neutron source facility is to train young nuclear specialists, therefore ANL has developed the KIPT Neutron Source Facility Simulator for this function. In this simulator, a Plant Control System and a Plant Protection System were developed to perform proper control and to provide automatic protection against unsafe and improper operation of the facility during the steady-state and the transient states using a facility plant model. This report focuses on describing the physics of the plant model and provides several test cases to demonstrate its capabilities. The plant facility model uses the PYTHON script language. It is consistent with the computer language of the plant control system. It is easy to integrate with the simulator without an additional interface, and it is able to simulate the transients of the cooling systems with system control variables changing on real-time.
\end{abstract}




\section{PLANT MODEL OF KIPT NEUTRON SOURCE FACILITY SIMULATOR}

\section{Introduction}

Argonne National Laboratory (ANL) of the United States and Kharkov Institute of Physics and Technology (KIPT) of Ukraine are collaborating on constructing a neutron source facility at KIPT, Kharkov Ukraine [1]. The facility has a 100-kW electron beam driving a subcritical assembly (SCA). The electron beam interacts with a natural uranium target or a tungsten target for generating neutrons, and it deposits its energy in the target zone. The fission power generated in SCA is about $300 \mathrm{~kW}$. Two primary cooling loops are used to remove $100-\mathrm{kW}$ and $300-\mathrm{kW}$ from the target zone and the SCA, respectively. A secondary cooling system is coupled with the primary systems to dispose of the heat outside the facility buildings to the atmosphere. In addition, the electron accelerator has a low efficiency for generating the electron beam, which uses another secondary cooling loop to remove the generated heat from the accelerator primary cooling loop.

One of the main functions the KIPT neutron source facility is to train young nuclear scientists in Ukraine, therefore ANL developed the KIPT Neutron Source Facility Simulator (KIPT-NSFS) to train future facility operators and young nuclear scientists [2]. In this simulator, a Plant Control System (PCS) and a Plant Protection System (PPS) were developed to exercise proper control and to provide automatic protection against unsafe and improper operation of the facility during the steady-state and the transient states using a plant model [3]. The PCS and the PPS are interconnected to the major systems of the neutron source facility. The control software Experimental Physics and Industrial Control System (EPICS) [4] and the Control System Studio (CSS) are utilized to implement the process variable database and the sequence logic. Previously, the PCS was tested with a plant simulator program called G-PASS/SCM written in FORTRAN, and utilized a separate bridge program in Python language for demonstration purposes. The process relies on a handshake class to communicate between the plant model and the EPICS control. An I/O file which was created and written by one program and it was read by another program. There are several discrepancies exist in this approach, and a number of additional interfaces were required [1]. For instance, the G-PASS/SCM plant system model is an approximate model. Some of the control and process variables have to be combined together in order to match the variables in EPICS. In addition, the G-PASS/SCM program is limited to simulate a set of predefined transients, and cannot provide the flexibility of changing the plant control components freely in a training session. ANL developed a new plant model for providing the flexibility of changing the plant system status in NSFS. This plant model was written in PYTHON [5] which is consistent with the computer language of the EPICS control software, and it is easy to integrate with the simulator without additional interfaces. It is also capable of simulating the transients of the cooling systems with system control variables changing on real-time. 
This report focuses on describing this plant model, which is used in the NSFS. The physics models of the different components are described in Section I. The numerical models of the KIPT primary cooling loops and the secondary cooling loops are briefly included in Section II. Section III includes several test cases for the KIPT cooling loops demonstrating the capabilities of the simulators, and a brief summary is given in Section IV.

\section{Physics Model of the Plant Components}

The purpose of this plant model is to simulate the neutron source facility performance during normal operation states and transient conditions. Physical models were developed for the different components of the facility and the inlet and the outlet parameters of each component were defined. They were integrated through these parameters to simulate the facility performance. In addition, a capability was included to accelerate the component response to allow a reasonable time for searching the equilibrium status in the training session. In this section, the different models and their parameters are presented.

\section{Single Phase Tank Physical Model}

The single phase tank is often used to collect and hold the fluid at certain conditions. It is a tank which is always filled with the fluid. Figure 1 shows a schematic representation of the component, where " $\mathrm{m}$ " represents the total mass of the fluid in the tank, " $P$ " represents the pressure, "T" represents the temperature, " $Z$ " represents the gravity level, and "W" represents the mass flow rate of the fluid.

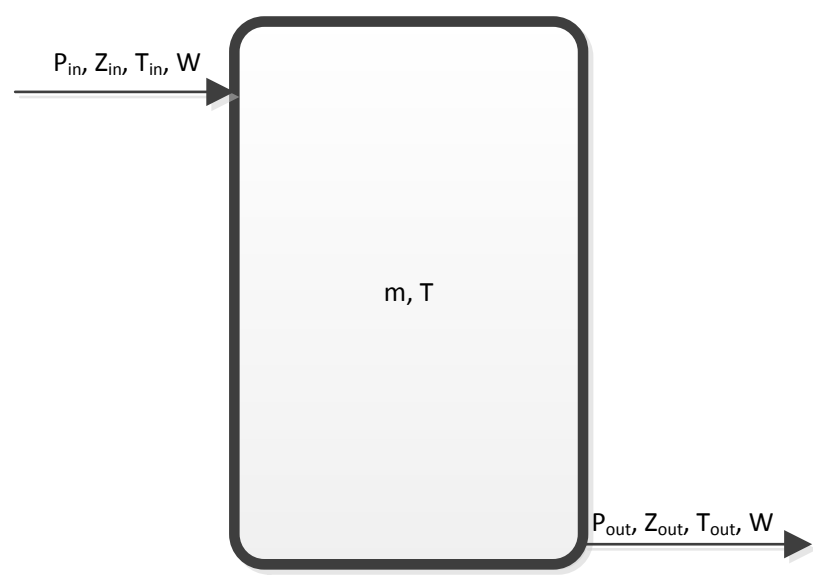

Figure 1. Schematic representation of the physical model of a single phase tank.

Assuming that the fluid is instantly mixed at any time inside the tank, a simple physics model of this tank can be derived as:

$$
P_{\text {in }}-P_{\text {out }}=\rho g\left(Z_{\text {out }}-Z_{\text {in }}\right),
$$




$$
T_{\text {out }}=T_{1}=T_{0}+\frac{\mathrm{W} \Delta t}{m}\left(T_{\text {in }}-T_{0}\right) .
$$

Where, $\rho$ is the mass density of the fluid, $g$ is the standard acceleration due to free fall, subscript "in" and "out" represent the state variable at the inlet and outlet of the tank respectively, and subscript " 0 " and " 1 " represents the state variable at two consecutive states, i.e., $T_{0}$ and $T_{1}$ are the old and the new temperatures of the fluid mixture inside the tank for the two consecutive states. Similar labels using these subscripts to represent the system state variables are used very frequently in the rest of the model derivation, and it will not be explained again in the report. The variable $\Delta t$ is always the time interval between the two consecutive states and it is used consistently in the report.

\section{Two Phase Tank Physical Model}

A two phase tank has both the fluid and the gas in the tank as shown in Figure 2, where $\gamma$ is the cross section area of the two phase tank, and $L$ represents the level of the fluid inside the tank, $P_{a}$ is the pressure above the fluid surface due to the existence of the gas. Assuming the fluid inside the two-phase tank is mixed instantly at any moment with a temperature $\mathrm{T}$, the physics model for the two phase tank can be written as following:

$$
\begin{gathered}
P_{\text {out }}=P_{a}+\rho g L, \\
L_{1}=L_{0}+\frac{\left(W_{\text {in }}-W_{\text {out }}\right) \Delta t}{\gamma}, \\
T_{\text {out }}=T_{1}=\frac{m-W_{\text {in }} \Delta t}{m} T_{0}+\frac{W_{\text {out }} \Delta t}{m} T_{\text {in }} .
\end{gathered}
$$

Where, $m, P, W, T$ and $L$ have the same definitions as in the single phase tank model.

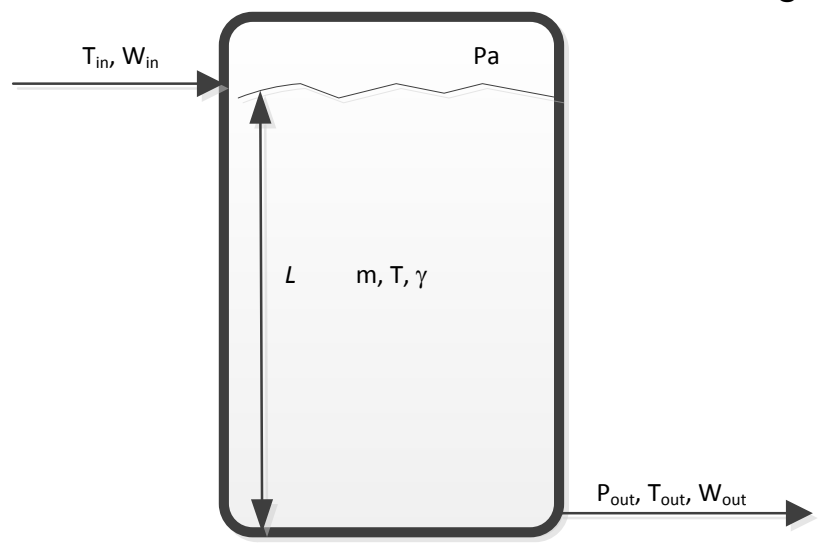

Figure 2. Schematic representation of the physical model of a two phase tank.

\section{Cooling Tower Physical Model}

The cooling towers dispose of the heat to the environment (atmospheric air). It is accomplished by transferring the heat between hot water droplets and ambient air. 
During normal operation, water loses was ignored and the makeup flow rate is zero. The cooling tower model adopted here is a simple one similar to the model developed by Stabat and Marchio [6] as shown in Figure 3.

The conservation of energy is applied to calculate the cooled water temperature and the warm air temperature leaving the tower.

$$
C_{w} W_{w}\left(T_{w i}-T_{w o}\right)=C_{a} W_{a}\left(T_{a o}-T_{a i}\right)=\epsilon C_{\min }\left(T_{w i}-T_{a i}\right),
$$

Where $T_{w i}$ is the water inlet temperature of the cooling tower, $T_{w o}$ is the water temperature before entering the cooling tower basin, $T_{a i}$ is the ambient air temperature, $T_{a o}$ is the outlet air temperature, $\mathrm{C}_{\mathrm{w}}$ and $C_{a}$ are the specific heat of the water and air respectively, and $C_{\min }$ is defined as:

$$
C_{\min }=\min \left(C_{w} W_{w}, C_{a} W_{a}\right) .
$$

$\varepsilon$ is a parameter depends on the type of the cooling tower, and can be determined based on the tower thermal conductance $U$, the heat transfer area of the cooling tower $A$, and the water and air flow rates $\left(W_{w}, W_{a}\right)$ passing through the cooling tower by the following calculations:

$$
\begin{gathered}
\theta=\frac{\min \left(C_{w} W_{w}, C_{a} W_{a}\right)}{\max \left(C_{w} W_{w}, C_{a} W_{a}\right)}, \\
N_{A}=\frac{U A}{C_{\min }}, \\
\psi=e^{-N_{A}(1-\theta),} \\
\epsilon=\frac{1-\psi}{1-\psi \theta} .
\end{gathered}
$$

The water level $L$ in the cooling tower basin, the pressure $P_{\text {out }}$, and cooled water temperature $T_{\text {out }}$ leaving out of the cooling tower basin are determined from the twophase tank model previously described:

$$
\begin{gathered}
P_{\text {out }}=P_{\text {air }}+\rho g L, \\
L_{1}=L_{0}+\frac{\left(W_{w}+W_{\text {in }}-W_{\text {out }}\right) \Delta t}{\gamma}, \\
T_{\text {out }}=T_{1}=\frac{m-W_{\text {out }} \Delta t}{m} T_{0}+\frac{W_{\text {in }} \Delta t}{m} T_{i}+\frac{W_{w} \Delta t}{m} T_{\text {wo }} .
\end{gathered}
$$

Where $\gamma, m$ and the water flow rates have the same definitions as in a two phase tank. The $W_{w}$ is the flow rate of the feeding water, $P_{\text {air }}$ is the ambient air pressure. 


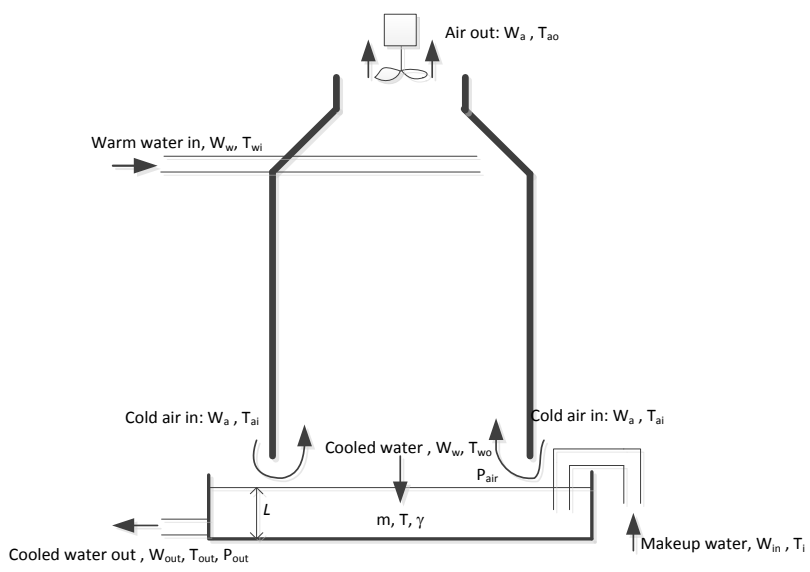

Figure 3. Schematic representation of the physical model of a cooling tower.

\section{Junction Node Physical Model}

The junction nodes occur where several segments of the cooling system are connected. Figure 4 represents a typical schematic presentation of a junction node. The fluids are instantly mixed at the junction node, and distributed to several segments after the junction node. Therefore, the out fluid temperatures at the junction node are all the same as the mixture temperature at the node $\mathrm{T}$ :

$$
\begin{gathered}
\sum_{i}^{m} W_{\text {in }, i}=\sum_{j}^{n} W_{\text {out }, j} \\
T_{\text {out }, j}=T_{1}=\frac{\sum_{i}^{m} W_{\text {in }, i} T_{\text {in }, i}}{\sum_{j}^{n} W_{\text {out }, j}} .
\end{gathered}
$$

The pressure at this junction node is not determined by this physics model, but rather by the segments connected at this node.

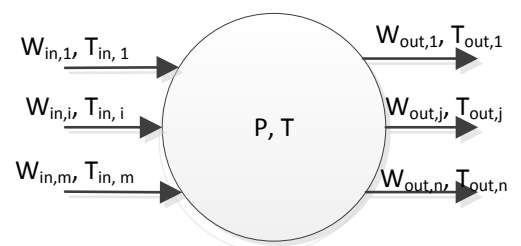

Figure 4. Schematic representation of the physics model of a junction node.

\section{Segment Physical Model}

A segment of a cooling system refers to a sub-loop of the system which utilizes a pipe to connect different components or junction nodes as shown in the schematic representation in Figure 5. 


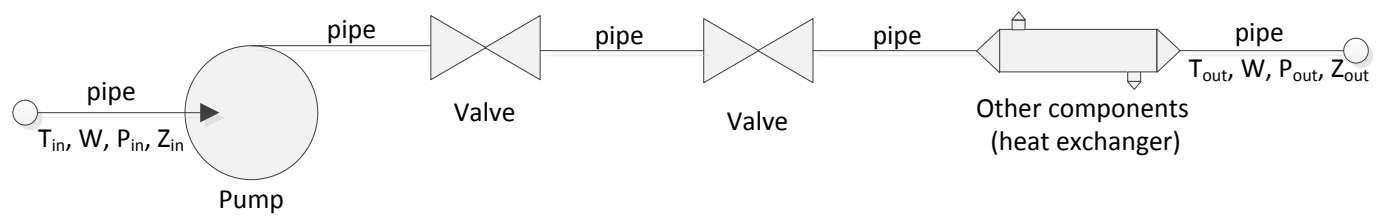

Figure 5. Schematic representation of the physics model of a segment.

The pressure drop over this segment is calculated as following:

$$
P_{\text {in }}-P_{\text {out }}-W|W|\left(k_{p}+k_{v}+k_{c}\right)+\Delta P_{\text {pump }}=\rho g\left(Z_{\text {out }}-Z_{\text {in }}\right),
$$

Where, the $k_{p}, k_{v}, k_{c}$ represent the resistances of the pipe segments, the valves, and other components respectively; and $\Delta P_{\text {pump }}$ is the pump head provided by the pump segment. The enthalpy is transferred from the beginning of the segment to the end of the segment assuming incompressible fluid:

$$
\begin{gathered}
T_{\text {out }}(t)=T_{\text {in }}(t-\tau), \\
\int_{t-\tau}^{t} W\left(t^{\prime}\right) d t^{\prime}=m,
\end{gathered}
$$

Where, $m$ is the total mass of the fluid inside the segment, $t$ represents the time point that the temperature sample is taken both at the inlet and outlet of the segment, and $\tau$ represents the amount of time for the fluid traveling from the inlet to the outlet. In this physical model, the pipe area is assumed to be constant. Thus, the flow through the segment is constant.

\section{Pump Physical Model}

A pump is a component of a cooling system providing mechanical forces to move the fluid inside the system as shown in Figure 6.

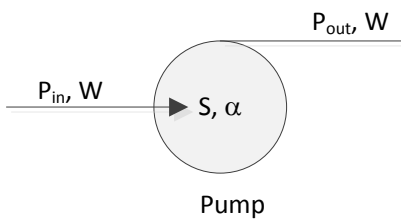

Figure 6. Schematic representation of the physical model of a pump.

It is characterized by its performance curve which shows the relation between the fluid flow rate $\mathrm{W}$ and the pump pressure head $\Delta P_{\text {pump }}$. This performance curve is provided by the pump manufacture, and it is fitted by the following function in the plant model:

$$
\Delta P_{\text {pump }}=P_{\text {out }}-P_{\text {in }}=S^{2}\left(P_{\text {max }}-\alpha W^{2}\right),
$$

Where, $\mathrm{S}$ is the pump speed having a value of 1.0 at full speed operations, $P_{\max }$ is the maximum head the pump can provide, and $\alpha$ is the coefficient characterizing the performance curve. 


\section{Block Valve Physical Model}

A block valve is a device used to regulate, to control or to direct the fluid flow in the cooling system. It can have more than two positions, and the positions can be controlled externally. In this plant model, only the "open" and the "closed" positions are considered. At the "open" position, the fluid can flow freely through the valve in both directions. At the "closed" position, the fluid is obstructed. The two positions of a block valve are modeled through different values of the resistance parameter " $k$ ":

$$
\left\{\begin{array}{cc}
\text { if closed } & K=10^{6} \\
\text { if open } & K=10^{-6}
\end{array}\right.
$$

It is set to an extremely large number $\sim 10^{6}$ when the valve is at the closed position, and set to a very small number of $\sim 10^{-6}$ when the valve is at the open position.

\section{Check Valve Physical Model}

A check valve or a one-way valve allows the fluid flowing through it in one direction. There are various types of check valves available, and these valves work automatically and they are not controlled externally. Figure 7 shows a schematic representation of a check valve.

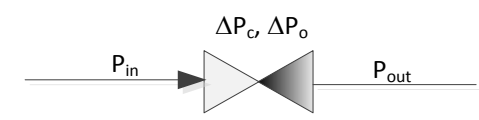

Figure 7. Schematic representation of the physical model of a check valve.

The important parameter which affects the check valve operation is the cracking pressure $\Delta \mathrm{P}_{\mathrm{c}}$ which is the minimum pressure at which the valve will operate. When the pressure at the outlet side is larger than the pressure at the inlet side by $\Delta \mathrm{P}_{\mathrm{c}}$, the check valve will be closed to block the flow. The vale will reopen when the pressure on the inlet side is larger than the pressure at the outlet side by $\Delta \mathrm{P}_{\mathrm{o}}$. The physical model of the check valve using the cracking pressure is described as follows:

$$
\left\{\begin{array}{lc}
\text { if } P_{\text {out }}>P_{\text {in }}+\Delta P_{c} & K=10^{6} \\
\text { if } P_{\text {in }}>P_{\text {out }}+\Delta P_{o} & K=10^{-6}
\end{array}\right. \text {. }
$$

\section{Relief Valve Physical Model}

A relief valve is a device to limit or to relieve the pressure built up in a cooling system due to an equipment failure. Normally it provides an auxiliary passage of the fluid/gas out of the system. The auxiliary route is forced open when the buildup pressure exceeds a set value $\Delta \mathrm{P}_{\mathrm{o}}$. As the fluid/gas is diverted, the pressure inside the system will drop. The valve closes after the pressure difference inside the system reaches a reseating pressure $\Delta \mathrm{P}_{\mathrm{c}}$. Figure 8 shows a schematic representation of the three-way relief valve, and its physics model can be simply described as: 


$$
\begin{aligned}
& \left\{\begin{array}{lc}
\text { if } P_{1}<P_{3}+\Delta P_{c 1} & K=10^{6} \\
\text { if } P_{1} \geq P_{3}+\Delta P_{o 1} & K=10^{-6}
\end{array}\right. \\
& \text { if } P_{2}<P_{3}+\Delta P_{c 2} \quad K=10^{6} \\
& \text { if } P_{2} \geq P_{3}+\Delta P_{o 2} \quad K=10^{-6}
\end{aligned}
$$

Where the $\Delta P_{c 1}, \Delta P_{c 2}$ are the reseating pressure of the relief valve and $\Delta P_{o 1}$ and $\Delta P_{o 2}$ are the pressure difference to open the relief route.

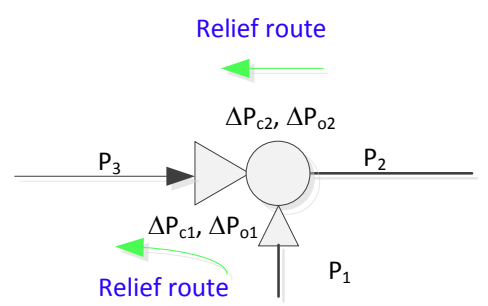

Figure 8. Schematic representation of the physics model of a relief valve.

\section{Single Phase Heat Exchanger Physical Model}

A heat exchanger is a component in the cooling systems for transferring the heat from one loop to another. The cold stream and the hot stream of the fluid/gas are separated by a solid wall to prevent mixing. In this plant model, the heat exchanger is modeled with a tube bundle followed by a single phase tank, as a schematic presentation shown in Figure 9.

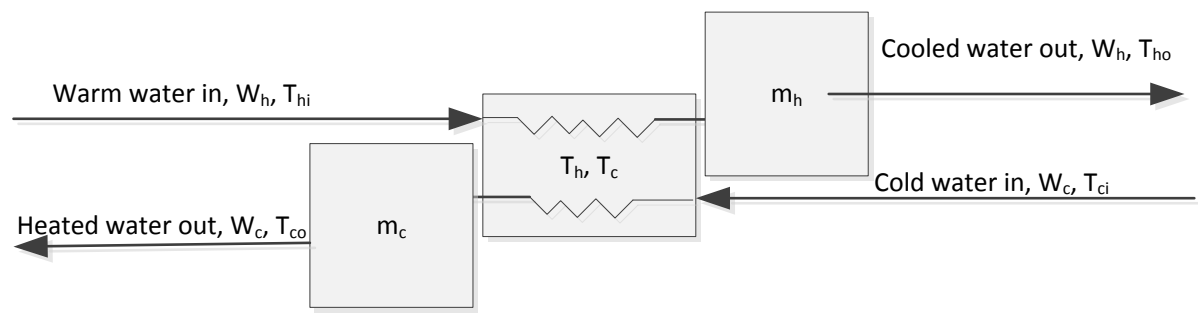

Figure 9. Schematic representation of the physical model of a heat exchanger.

As shown in this figure, the warm fluid with mass flow rate of $W_{h}$, and temperature of $\mathrm{T}_{\mathrm{hi}}$ encounters the cold fluid with mass flow rate of $W_{c}$, and temperature of $\mathrm{T}_{\mathrm{ci}}$ at the tube bundle. After exchanging the heat, the cooled water at the warm side of the heat exchanger is then instantly mixed with the fluid in a tank with total mass of $m_{h}$, and the heated water at the cold side is instantly mixed with the fluid in a tank with total mass of $m_{c} . T_{h}$ and $T_{c}$ represent the temperatures of the cooled fluid and the heated fluid leaving the bundled tube, respectively. Similarly to the model utilized in the cooling tower, for the tube bundle, the conservation of energy is applied to calculate both $T_{h}$ and $T_{c}$.

$$
C_{w} W_{h}\left(T_{h i}-T_{h}\right)=C_{w} W_{c}\left(T_{c}-T_{c i}\right)=\epsilon C_{\min }\left(T_{h i}-T_{c i}\right),
$$

Where:

$$
C_{\min }=\min \left(C_{w} W_{h}, C_{w} W_{c}\right),
$$


and $\varepsilon$ is determined using a procedure similar to the procedure used for the cooling tower model:

$$
\begin{gathered}
\theta=\frac{\min \left(C_{w} W_{h}, C_{w} W_{c}\right)}{\max \left(C_{w} W_{h}, C_{w} W_{c}\right)} \\
N_{A}=\frac{U A}{C_{\min }}, \\
\psi=e^{-N_{A}(1-\theta)}, \\
\epsilon=\frac{1-\psi}{1-\psi \theta} .
\end{gathered}
$$

The temperatures of both streams out of the heat exchanger on the hot side and cold side $T_{\text {ho }}, T_{\text {co }}$ are calculated using the single phase tank model developed previously:

$$
\begin{gathered}
T_{h o, 1}=T_{h o, 0}+\frac{W_{h} \Delta t}{m_{h}}\left(T_{h}-T_{h o, 0}\right), \\
T_{c o, 1}=T_{c o, 0}+\frac{W_{c} \Delta t}{m_{c}}\left(T_{c}-T_{c o, 0}\right) .
\end{gathered}
$$

\section{Single-Phase Heat Source Physical Model}

In a cooling system, a heat source is often a zone where the heat is generated and it is removed. In the physical model, the heat source can be modeled as a heater element and a single phase tank. Depending on the actual configuration, the single phase tank can be placed before or after the heater element as shown in the schematic representation (a) and (b) of Figure 10, respectively. $\mathrm{Q}$ is the amount of energy generated in the heat element, $\mathrm{m}$ is the total mass of fluid in the single phase tank, $W$ is the flow rate, $T_{i}, T_{h o}$ are the inlet and outlet temperature of the fluid respectively, and $T_{h}$ is the intermediate temperature of the fluid between the heater element and the single phase tank.

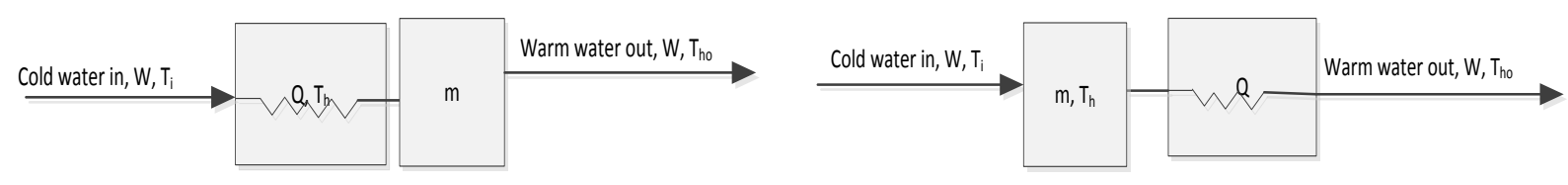

(a)

(b)

Figure 10. Schematic representation of the physical model of a heat exchanger (a) the tank after the heat element (b) the tank before the heat element.

Based on the above diagram, the outlet temperature for both cases can be easily calculated. For case (a): 


$$
\begin{gathered}
T_{h}=T_{i}+\frac{Q}{C_{w} W} \\
T_{h o, 1}=T_{h o, 0}+\frac{W \Delta t}{m}\left(T_{h}-T_{h o, 0}\right) .
\end{gathered}
$$

For case (b):

$$
\begin{gathered}
T_{h, 1}=T_{h, 0}+\frac{W \Delta t}{m}\left(T_{i}-T_{h, 0}\right), \\
T_{h o}=T_{h, 1}+\frac{Q}{C_{w} W} .
\end{gathered}
$$

\section{KIPT Cooling Systems}

The physical models described above were used to model the cooling systems of the KIPT neutron source facility as shown in Figures 11 to 14, where the orange lines represent the operating cooling lines in the SCA and target primary cooling loops at normal operations, the purple lines represent the cooling lines in the secondary cooling loops at normal operations, the blue lines represent the water drain systems for all the cooling loops, and the green lines represent the water cleanup systems in the primary cooling loops. In the plant model, the cooling systems were divided into different segments which are joined together through nodes, tanks and other system components. The pressure at the joint nodes or components is labeled as " $P$ " in the figure. The flow rates of each segment between the joint nodes together with the pressures are calculated by solving the momentum and continuity equations of the physical model of each component at each time step. The temperature is calculated sequentially using the physical models of the connected segments/nodes/components described in the previous section.

At normal operations, the total heat deposited in the KIPT subcritical tank is $\sim 300 \mathrm{~kW}$, the heat deposited in the target tank is $\sim 91 \mathrm{~kW}$, and the heat deposited in the accelerator primary loop is $\sim 1200 \mathrm{~kW}$. The water tank E22, E201 and E202 are modeled as single phase tanks for simplicity, the E1 water tank and all the other drain tanks are modeled as two phase tanks. The SCA tank is modeled as a heat source with the water tank before the heat element, and the target combined with the water tank E11 is modeled as a heat source with the water tank after the heat element. The pressure and flow rates in all of the four cooling systems are calculated separately. The SCA and the target primary loops are coupled with the secondary cooling system at the heat exchangers T1 and T20. The primary cooling loop of the accelerator is not modeled in this simulator. The heat removed from the accelerator primary coolant loop is deposited directly in the accelerator secondary cooling loop as a heat source with a tank after the heat element since the accelerator components are not simulated in this plant model. 


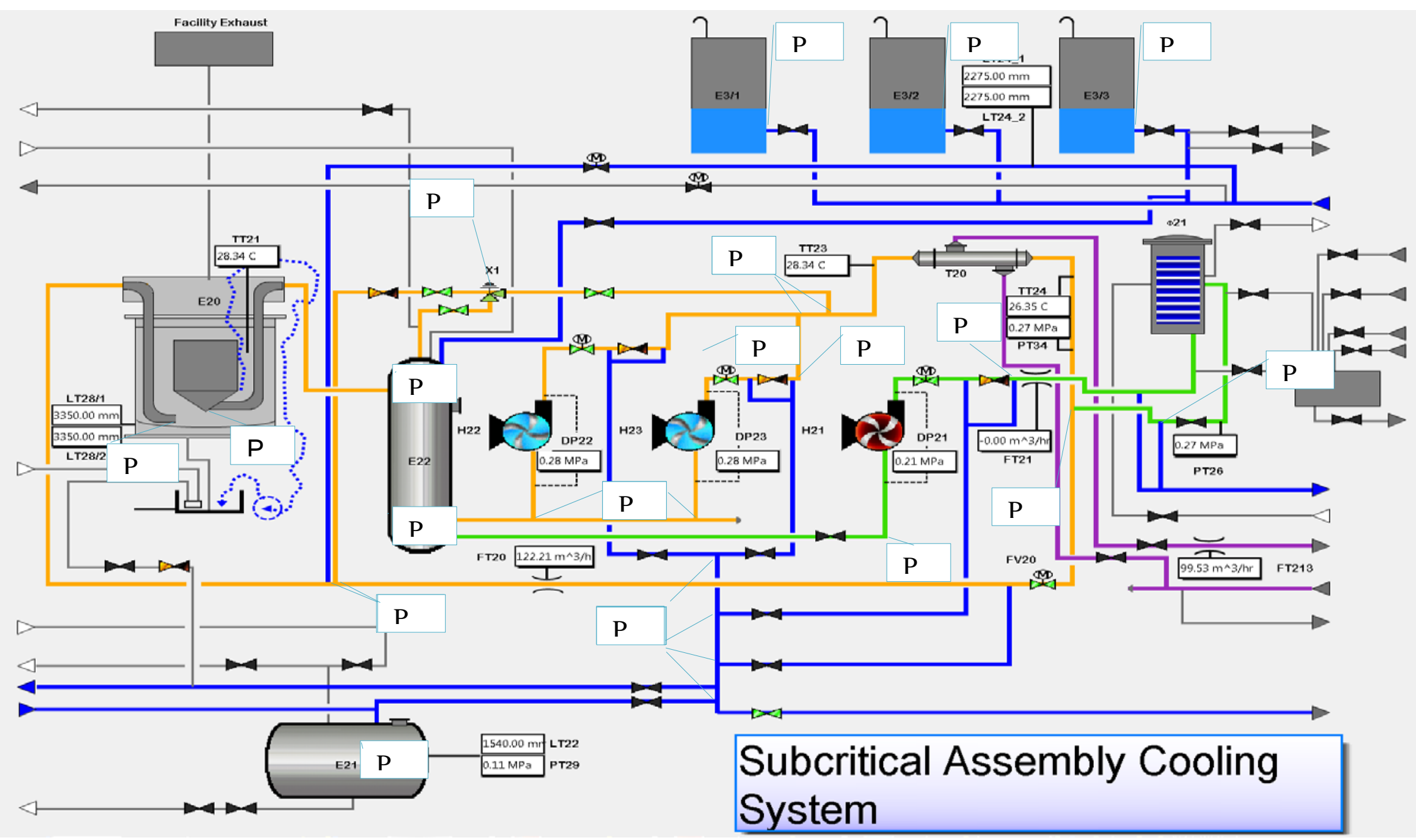

Figure 11. Plant physical model of the KIPT subcritical assembly primary cooling loop. 


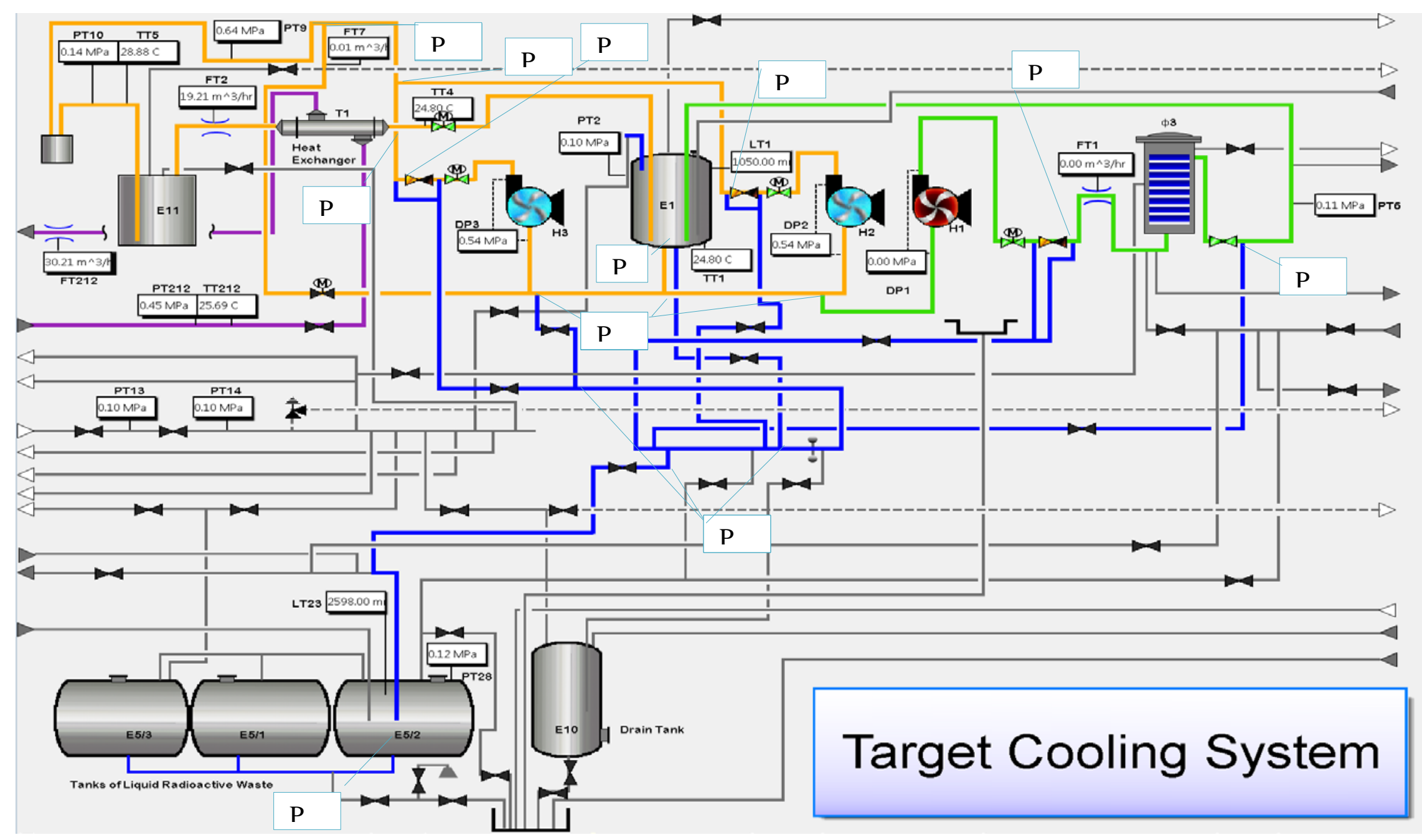

Figure 12. Plant model of the KIPT target primary cooling loop. 


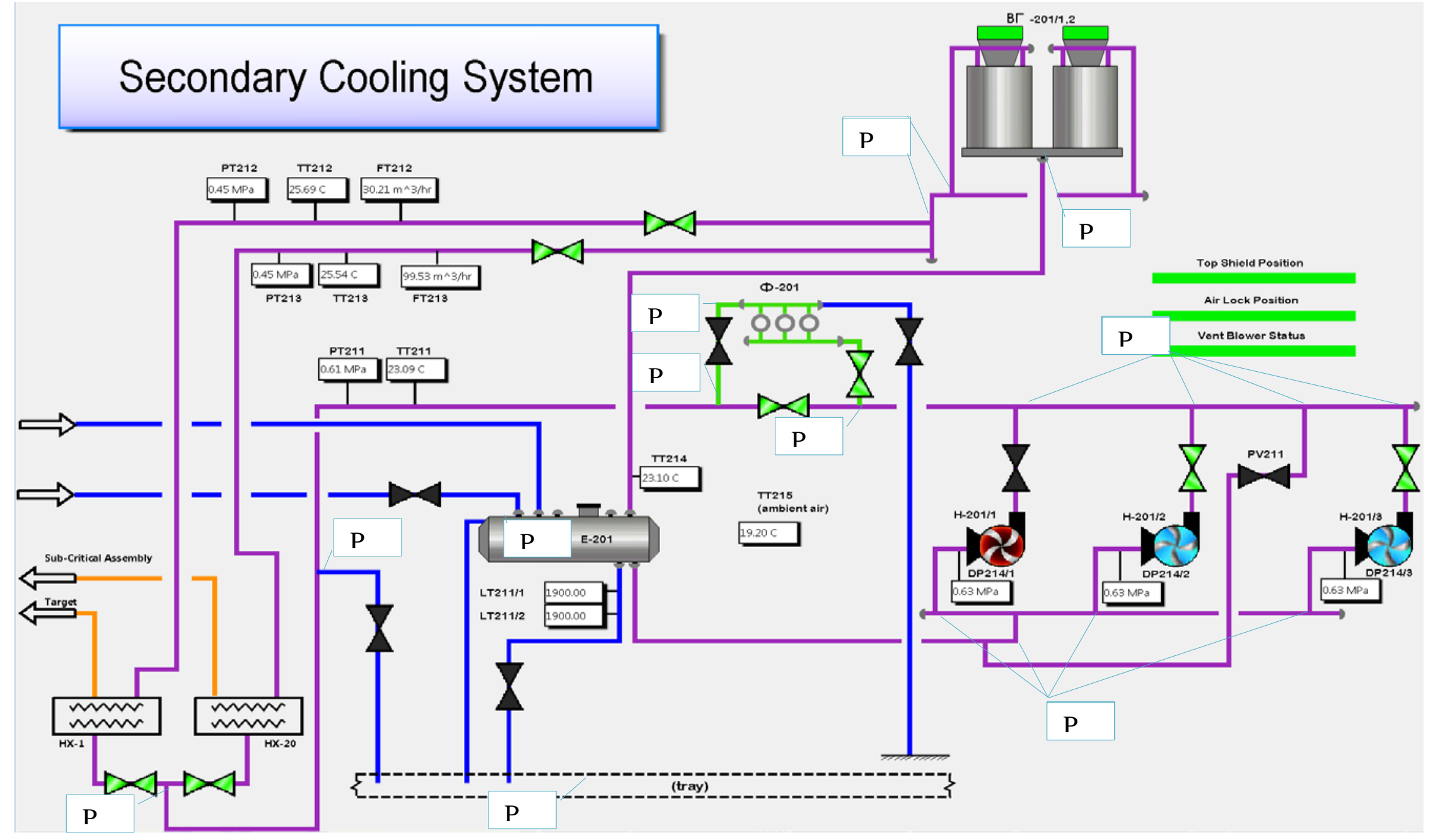

Figure 13. Plant model of the secondary cooling system of the KIPT subcritical assembly and the target primary cooling loops. 


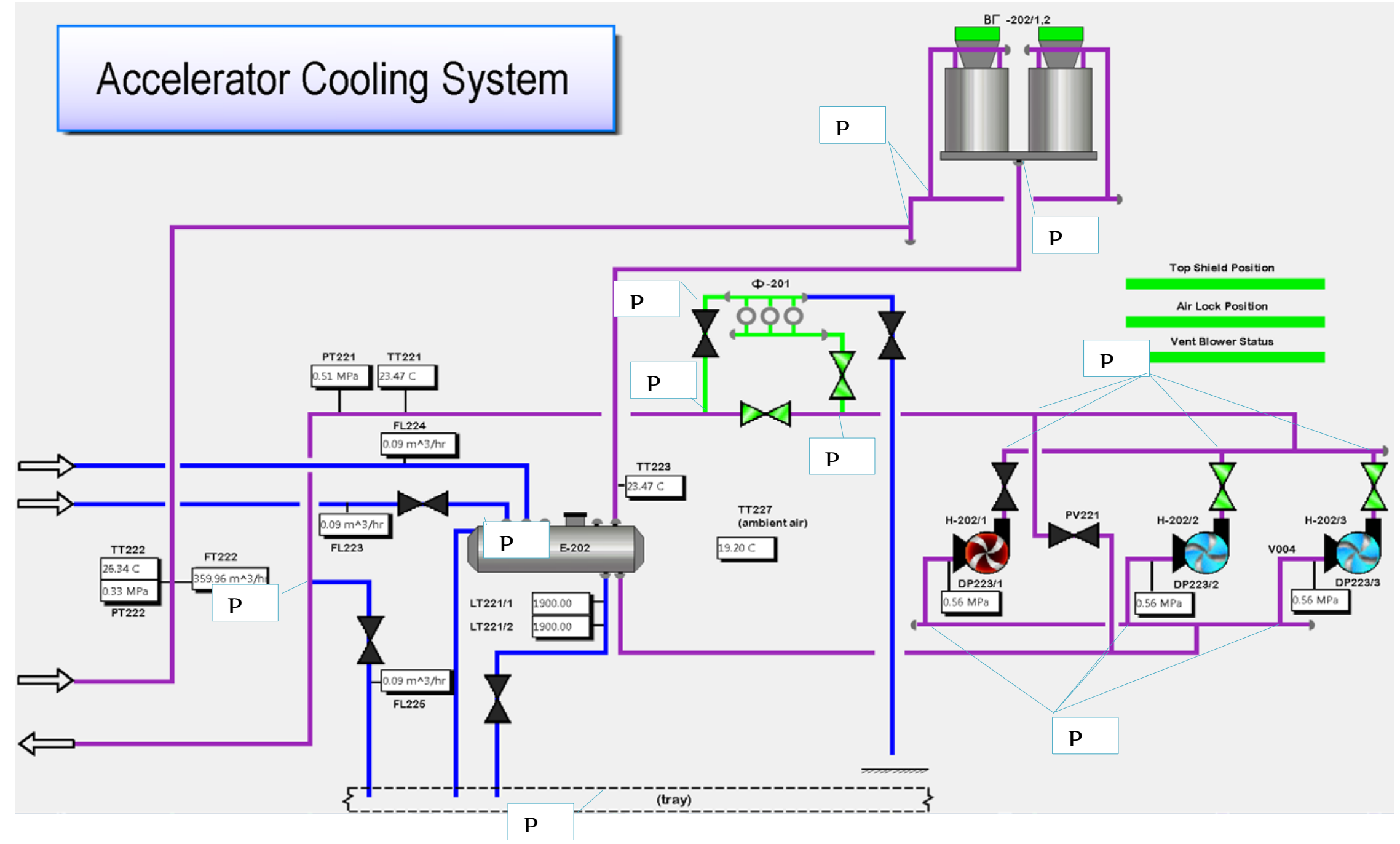

Figure 14. Plant model of the secondary cooling loop of the KIPT electron accelerator. 
Prior the transient simulations, the plant models are first initialized using the actual configurations of the KIPT cooling systems. The physical parameters, such as the resistance of each component " $\mathrm{k}$ " and thermal conductance of the heat exchangers " $U$ ", are determined by taking snap shots of the pressures, the flow rates, and the temperatures from the KIPT cooling system configurations.

EPICS passes the initial component positions to the plant model before any simulation. The initial pressure and flow rates are then calculated at each segment and junction node by the plant model. The initial temperatures in the cooling systems are searched as an equilibrium through accelerated iterations inside the cooling systems. Specifically, the temperature is assumed to be propagated from the beginning of every segment to the end of the segment immediately. The mixture at the water tanks also takes the updated inlet temperature immediately ignoring any component delay time.

The status of each of the components in the KIPT cooling systems is set through control functions. Appendix A lists the control functions for: valve opening or closing, pump on or off, accelerator power on or off, air blowers on or off, and other initial conditions of the facility. In the simulator, the software EPICS reads any change of the component status and pass the change to the plant model with a trigger signal defining the change time of the status.

To simulate the transients in the cooling systems such as startup, shutdown, or transient scenarios, a procedure is developed to calculate and to adjust automatically the time steps. The time step is controlled by the fastest increase or decrease of the coolant temperature. For the secondary loop of the subcritical assembly and the target primary loops, the time step is determined by:

$$
\delta \mathrm{t}=\delta \mathrm{t}^{\prime} * \mathrm{f}\left(\frac{\delta T_{c t w r}}{T_{c t w r}(t)}, \frac{\delta T_{T 1}}{T_{1}(t)}, \frac{\delta T_{20}}{T_{20}(t)}\right),
$$

Where $\delta \mathrm{t}^{\prime}$ is the previous time step, and $\mathrm{f}$ is an adjusting factor which is a function of the temperature variations $\frac{\delta T}{T}$ at the heat source (heat exchanger T1 and T20) and at the heat sink (cooling tower) of the cooling loop:

$$
\mathrm{f}\left(\frac{\delta T_{c t w r}}{T_{c t w r}(t)}, \frac{\delta T_{T 1}}{T_{1}(t)}, \frac{\delta T_{20}}{T_{20}(t)}\right)=\frac{\epsilon_{T}}{\max \left(a b s\left(\frac{\delta T_{c t w r}}{T_{c t w r}(t)}, \frac{\delta T_{T 1}}{T_{1}(t)}, \frac{\delta T_{20}}{T_{20}(t)}\right)\right)} .
$$

Similar calculations will also be made for other cooling loops. Then, with four cooling loops coupled, the actual time step is the minimum time step among all the loops. For the KIPT plant model, $\epsilon_{T}$ is chosen to be about 0.001 . Meanwhile, a minimum time step of 0.01 second and a maximum time step of 1.0 second are also implemented to allow the plant model to have a smooth change and fast responses toward the change of component status. 


\section{Test Cases}

Several test cases with the plant systems running at normal conditions and transient scenarios were simulated. The NSFS simulator was used to communicate with the plan model and display the plant model results.

\section{Steady State Operation}

The first test case simulates the KIPT facility operating at steady state, with one pump operated at full speed or two pumps operated at either half or full speed in the SCA and target primary loops. At steady state, all the valves on the drain line segments are closed. Other valves are open. The pump of the water cleanup systems are off. The thermal powers deposited in the cooling loops have the maximum values.

Figures 15 to 18 show the calculated values of all the pressure sensors, the flow rate sensors, and the temperature sensors in each cooling loop while the KIPT facility is operated at steady state for $100 \mathrm{~s}$, with only one pump in each of the SCA and target primary cooling loops operated at full speed. Figures 19 to 22 show the sensor values while two pumps in the SCA and target primary loops are operated at half speed or at full speed respectively. In all these test cases, two of the three pumps in both secondary cooling loops are operated at full speed. The pressure, the flow rates, and its temperature distributions are the same as shown in Figures 17 and 18. 

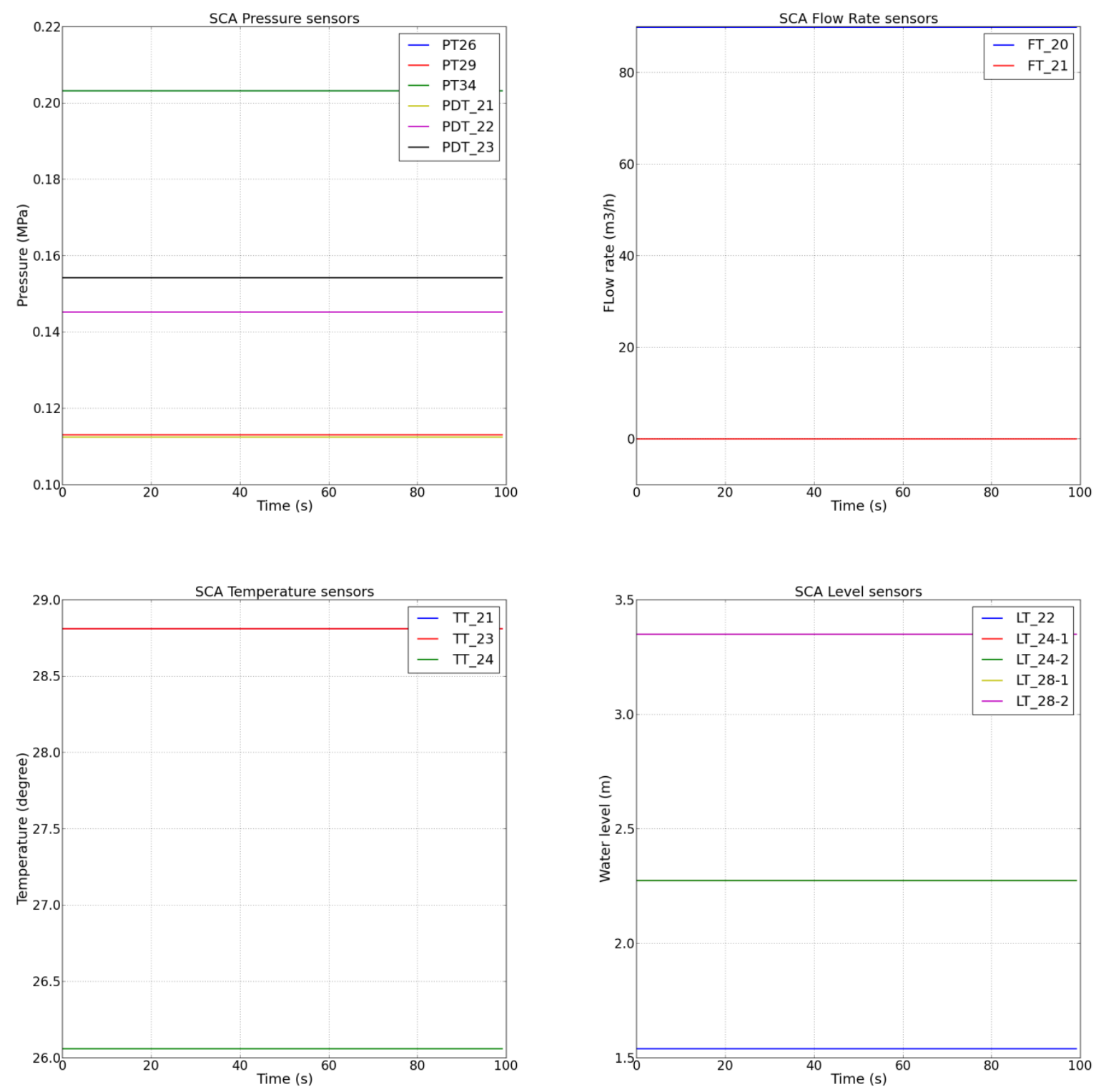

Figure 15. Calculated pressure, total flow rate, and temperature values of the SCA primary cooling loop with pump H22 operating at full speed and the KIPT neutron source facility is operating at steady state for $100 \mathrm{~s}$. 

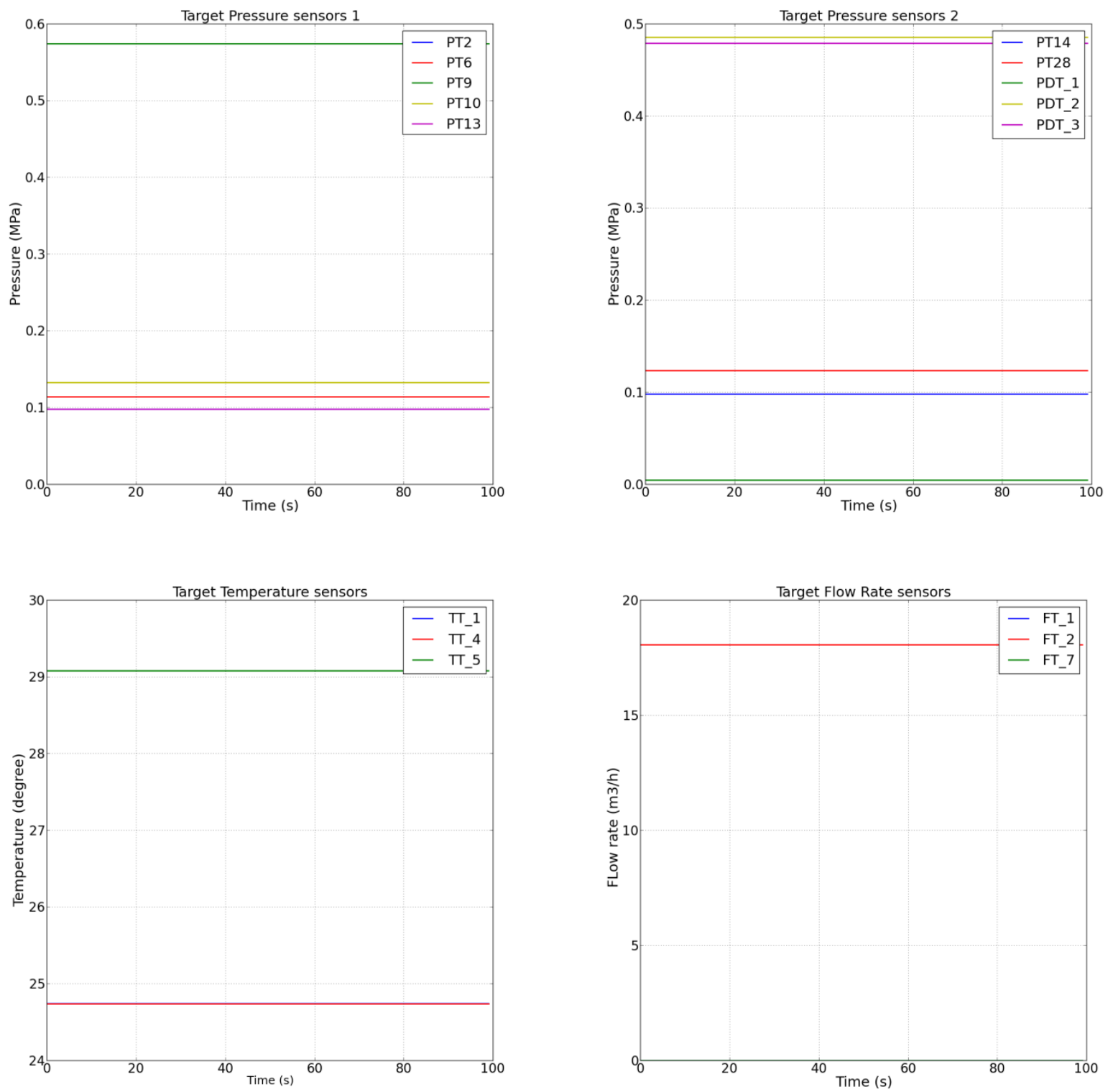

Figure 16. Calculated pressure, total flow rate, and temperature values of the target primary cooling loop with pump $\mathrm{H} 2$ operating at full speed and the KIPT neutron source facility is operating at steady state for $100 \mathrm{~s}$. 

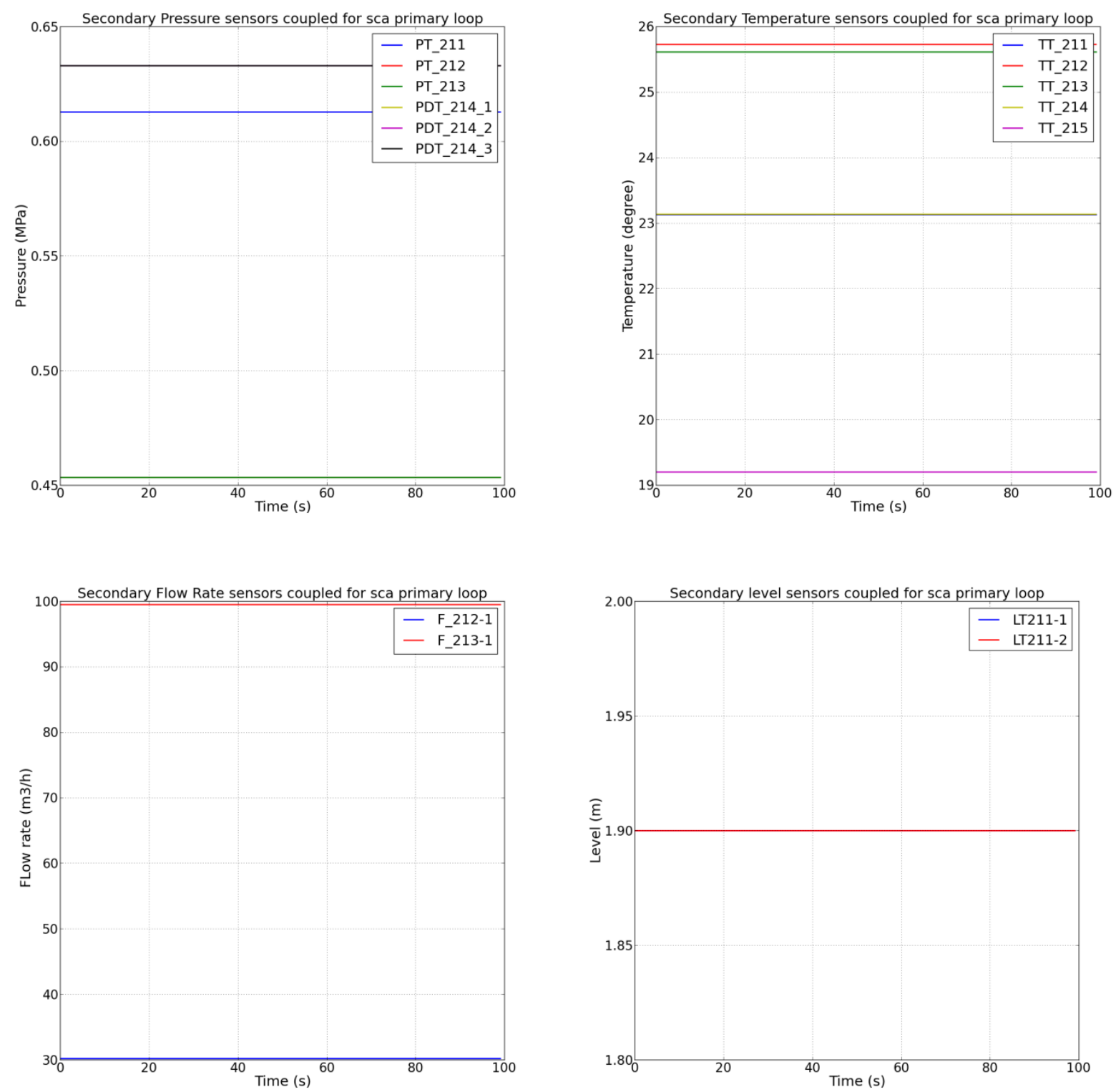

Figure 17. Calculated pressure, total flow rate, and temperature values of the secondary cooling loop coupled of the SCA and target primary loops with pump Z-201/1 and Z-201/2 operating at full speed and the KIPT neutron source facility is operating at steady state for $100 \mathrm{~s}$. 

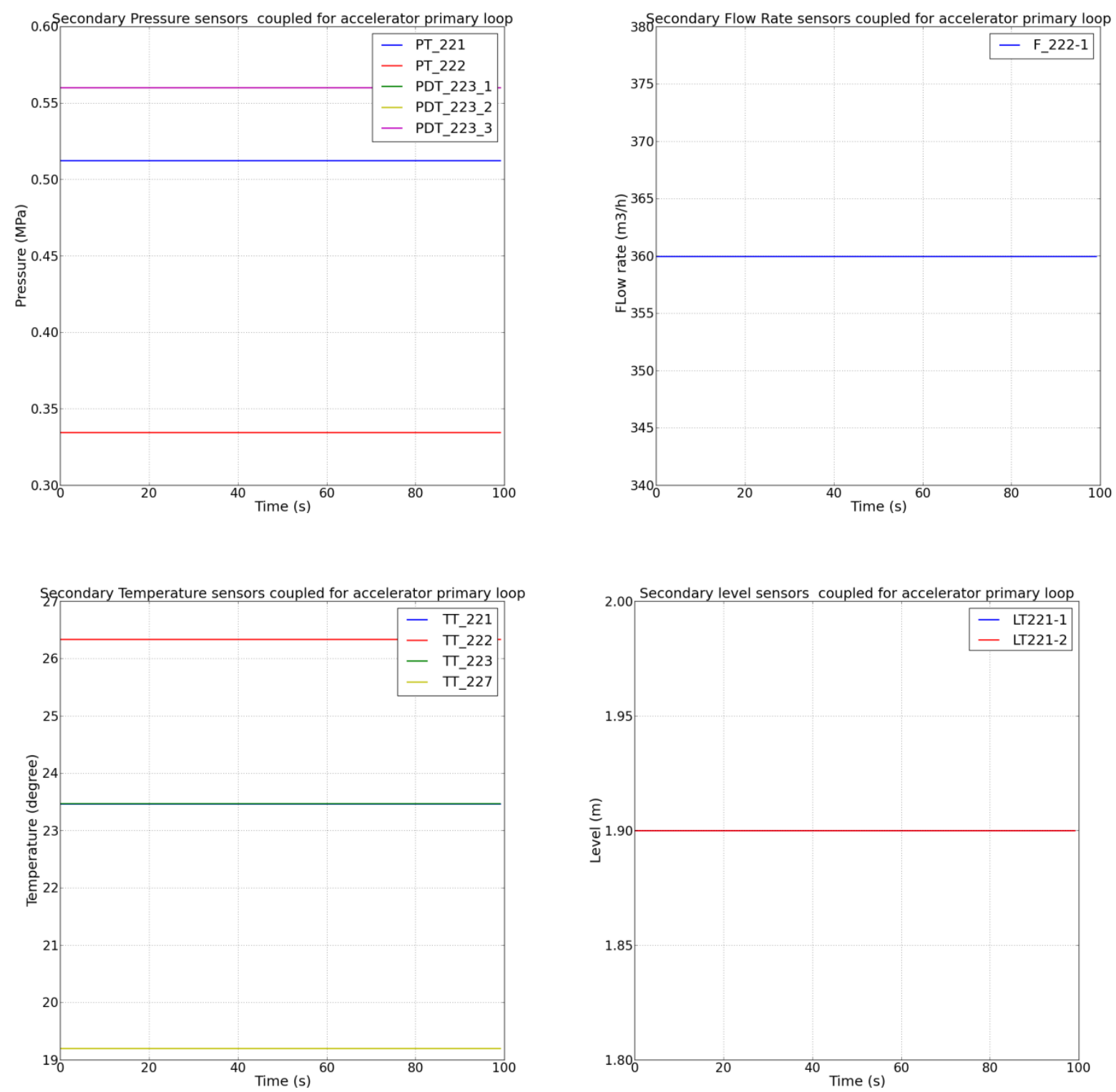

Figure 18. Calculated pressure, flow rate, and temperature values of the KIPT secondary cooling loop coupled with the accelerator primary systems at steady state with pump Z-202/1 and Z-202/2 operating at full speed and the KIPT neutron source facility is operating at steady state for $100 \mathrm{~s}$. 

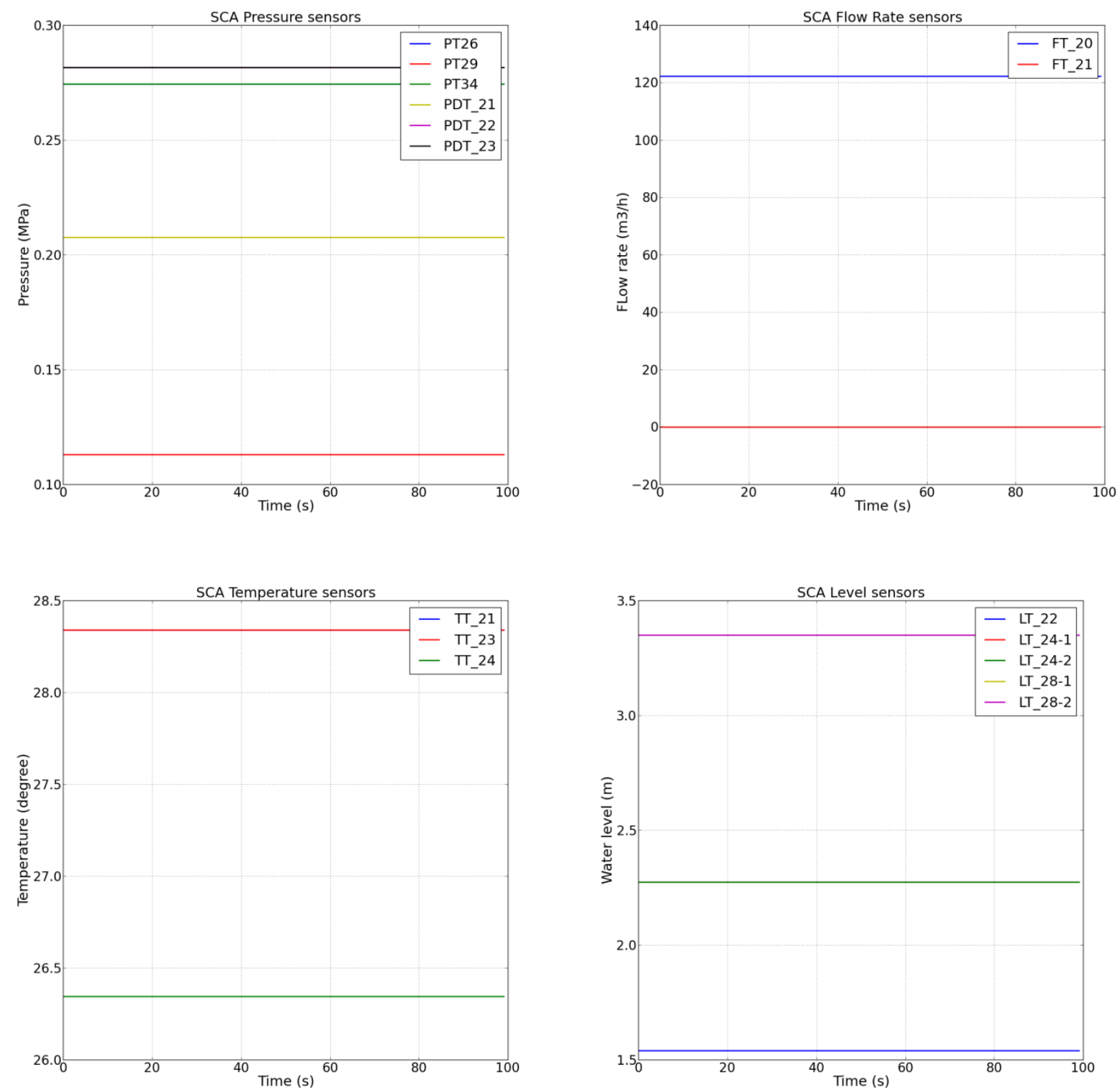

Figure 19. Calculated pressure, total flow rate, and temperature values of the subcritical assembly primary cooling loop with pump $\mathrm{H} 22$ and $\mathrm{H} 23$ operating at full speed and the KIPT neutron source facility is operating at steady state for $100 \mathrm{~s}$. 

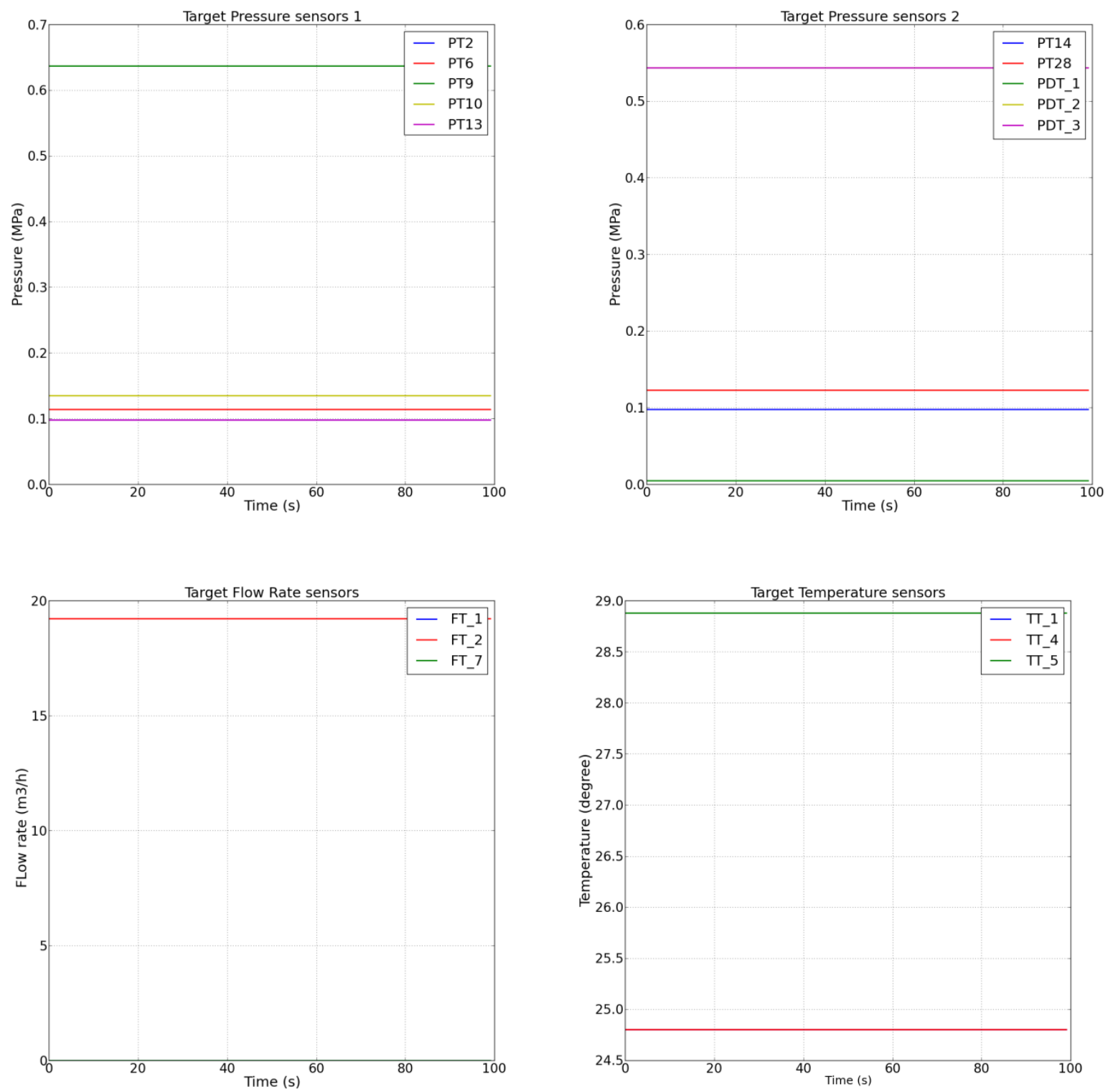

Figure 20. Calculated pressure, total flow rate, and temperature values of the target primary cooling loop with pump $\mathrm{H} 2$ and $\mathrm{H} 3$ operating at full speed and the KIPT neutron source facility is operating at steady state for $100 \mathrm{~s}$. 

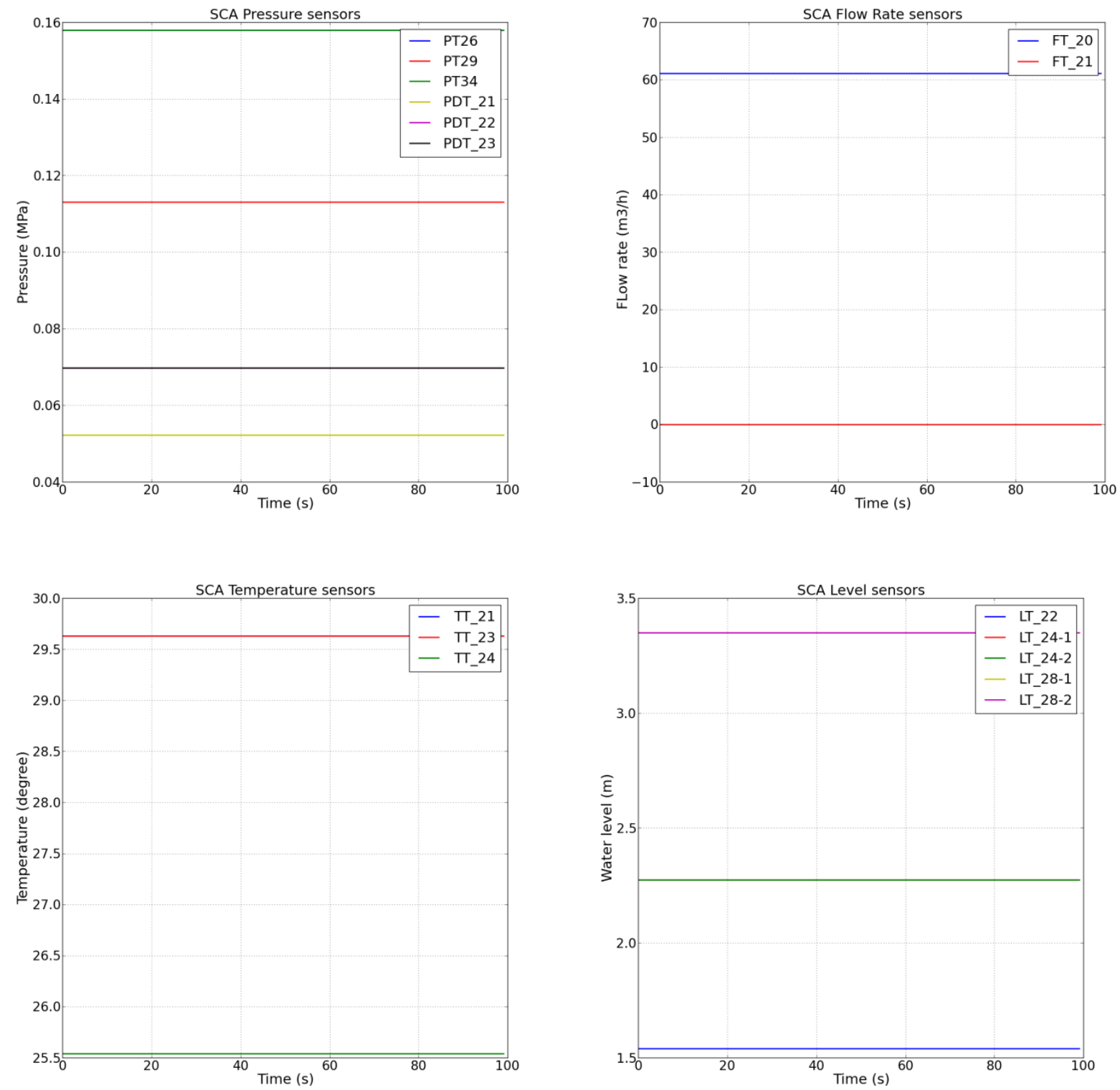

Figure 21. Calculated pressure, total flow rate, and temperature values of the subcritical assembly primary cooling loop with pump $\mathrm{H} 22$ and $\mathrm{H} 23$ operated at half speed and the KIPT neutron source facility is operating at steady state for $100 \mathrm{~s}$. 

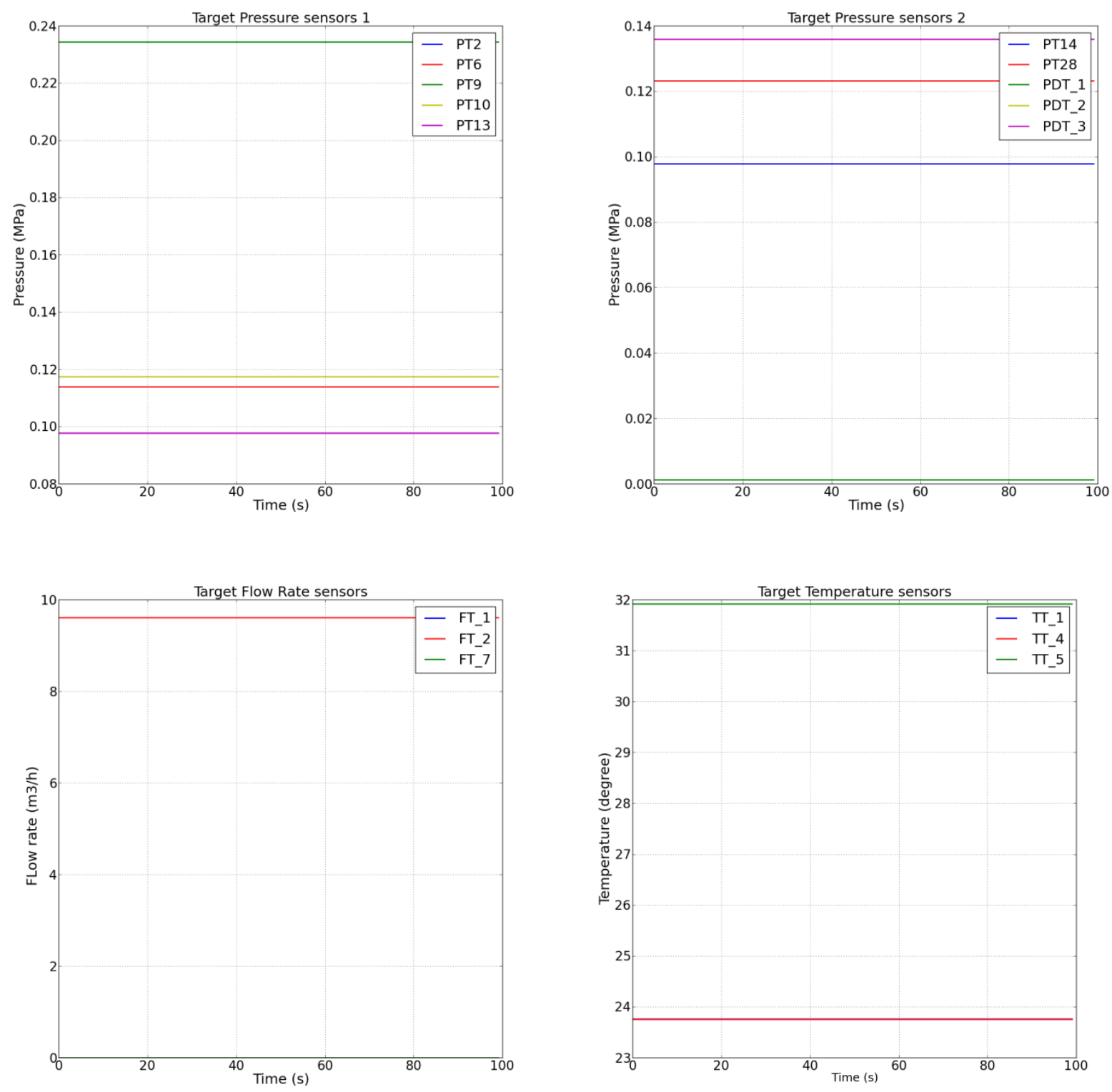

Figure 22. Calculated pressure, total flow rate, and temperature values of the target primary cooling loop with pump $\mathrm{H} 2$ and $\mathrm{H} 3$ operating at half speed and the KIPT neutron source facility is operating at steady state for $100 \mathrm{~s}$.

Overall, the initial temperature values obtained through the equilibrium search are steady state values for those sensors, and remain constants all the time in this null transient. The total flow rates for the case with only one pump running in the primary loops are calculated to be about $89.9 \mathrm{~m}^{3} / \mathrm{h}, 18.1 \mathrm{~m}^{3} / \mathrm{h}, 129.7 \mathrm{~m} 3 / \mathrm{h}$ and $360.0 \mathrm{~m} 3 / \mathrm{h}$ for the subcritical assembly primary cooling loop, the target primary cooling loop, the secondary cooling loop coupled with the subcritical assembly and target primary loops, and the secondary cooling systems coupled with the accelerator primary loop, respectively. Using two pumps operated at full speed can increase the flow rates 
running through the SCA primary loop by $\sim 35 \%$ and $\sim 10 \%$ in the target primary loop. In addition, the calculated results show that using two pumps each operated at half speed do not provide the same amount of flow rates compared with using one pump at full speed.

\section{Start-Up}

A set of conditions has to be satisfied to startup the KIPT neutron source facility. In this test case, only the conditions or the actions related to the plant model are discussed. The air blowers of the cooling towers are started first, followed by the secondary coolant loop pumps, and the SCA and target primary pumps. Then the accelerator is started and the coolant temperatures increases simultaneously.

To start the simulations, all the valves of the drain lines and the cleanup systems are closed. The plant system model starts from the shutdown position with all the pumps are off. The cooling tower air blowers are switched on after receiving a trigger signal from the EPICS $50 \mathrm{~s}$ from the start-up. Their air flow rates of the cooling towers are monitored. Then the cooling pumps of the different loops are turned on in the following sequence: Z-201/1, Z-201/2, Z-202/1, and Z-202/2 pumps at $100 \mathrm{~s}$, the H2 pump of the target primary cooling loop at $150 \mathrm{~s}$, and the $\mathrm{H} 22$ pump of the SCA primary loop at 200s. The accelerator power starts at 250s. These time intervals do not imply the actual operation of the KIPT neutron source facility, but are chosen only for demonstration purpose. The duration time of each action is set to 3 seconds also for demonstration purpose, which does not reflect the actual physical time taking by each component. The ambient air temperature is set at $19.2^{\circ} \mathrm{C}$ for the cooling towers, and the initial water temperature is set at $20^{\circ} \mathrm{C}$ in the plant model.

Figures 23 to 26 show all the sensor readings of each cooling loop for the first 500 seconds. The water flow rates and pressure values increase rapidly to reach the steady state values after starting the loop pumps. However, the temperatures of the different cooling loops take more time to reach the steady state values because of the thermal inertia of each loop. Figure 27 shows the temperature variations of four cooling loops for the first $5000 \mathrm{~s}$ of operation. The temperature values are increasing to reach the steady state calculated previously in the steady state case. The values of the temperature sensors TT21, TT5, and TT222 increase instantly, and the values of other temperature sensors also increase after a short delay depending on their locations from the heat source. The temperature sensors TT214 and TT223 monitor the outlet temperatures of the cooling towers for both secondary loops, respectively. Figures 25 and 26 show the temperature values of these two temperature sensors gradually decrease first. Because the air blowers are turned on at 50s and the ambient air temperature is lower than the water temperatures and it cools the water in the secondary loop first. Both sensor temperatures increase shortly after starting the accelerator. 

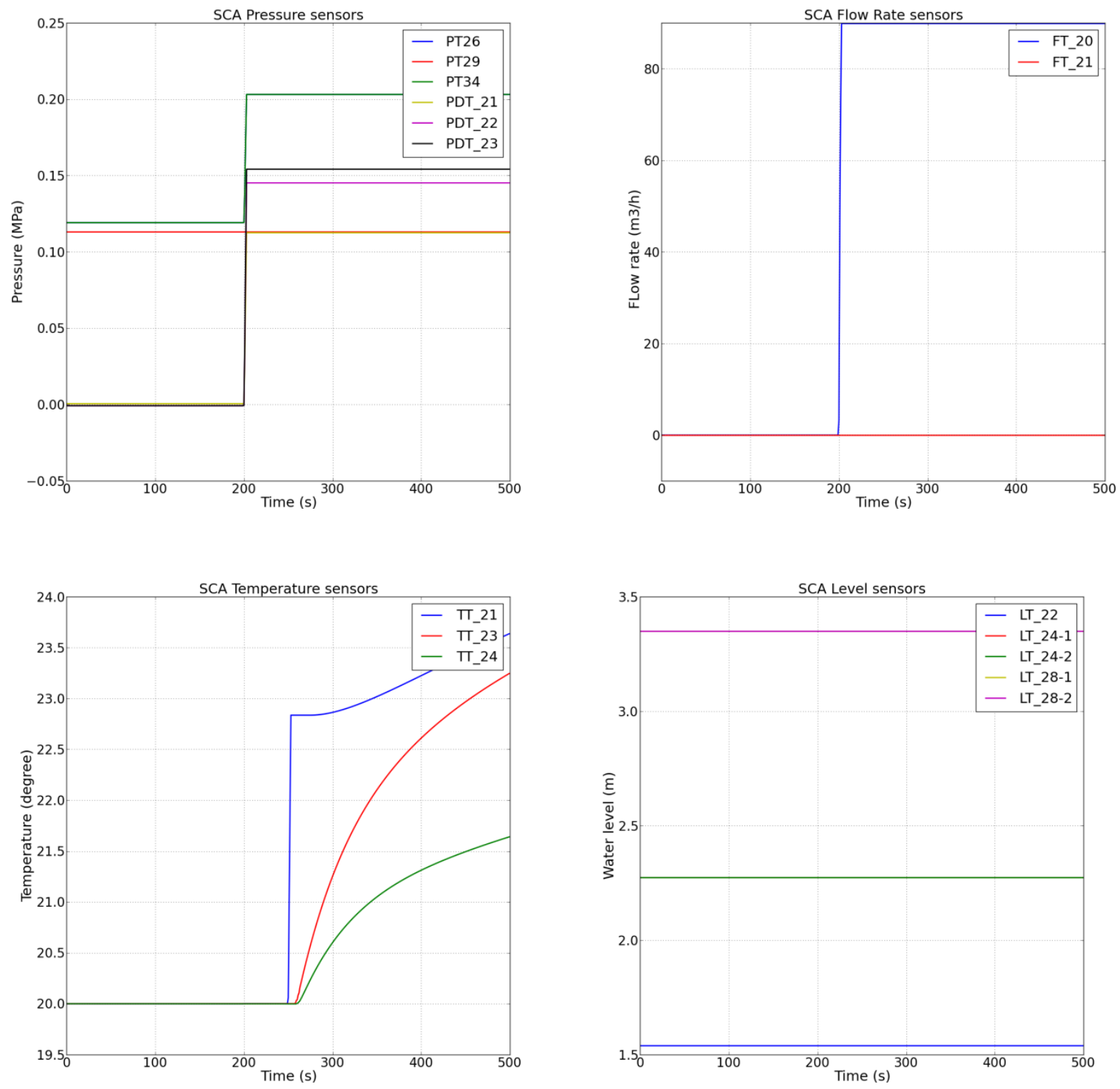

Figure 23. Calculated pressure, total flow rates, and temperatures of the SCA primary cooling loop with pump H22 operating at full speed and the KIPT neutron source facility starts from cold shutdown for 500 s operating time. 

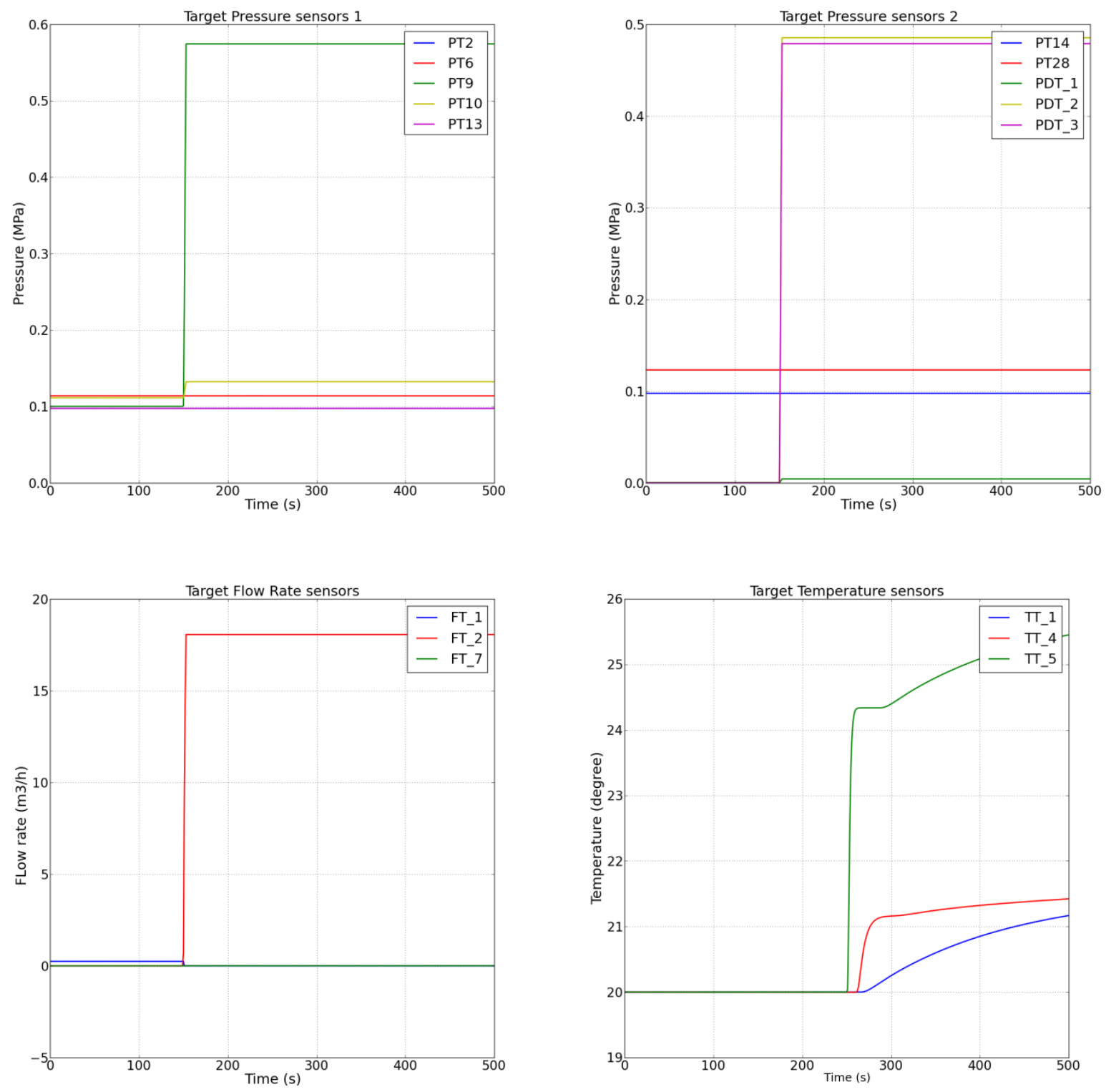

Figure 24. Calculated pressure, total flow rates, and temperatures of the target primary cooling loop with pump $\mathrm{H} 2$ operating at full speed and the KIPT neutron source facility starts from cold shutdown for 500 s operating time. 

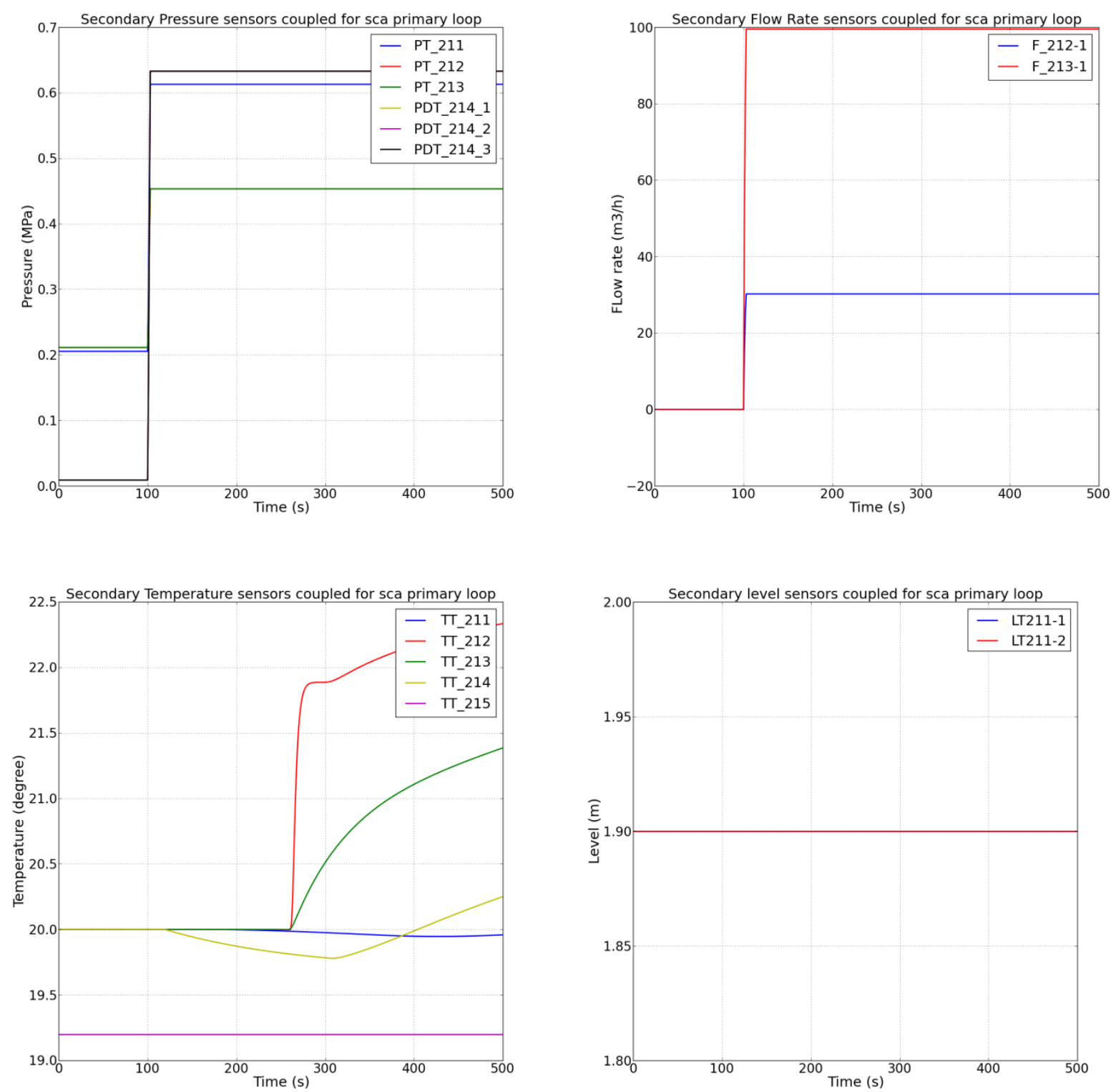

Figure 25. Calculated pressure, total flow rates, and temperatures of the secondary cooling loop coupled with the subcritical assembly and target primary cooling loops and pump Z-201/1 and Z-201/2 operating at full speed and the KIPT neutron Source facility starts from cold shutdown for 500 s operating time. 

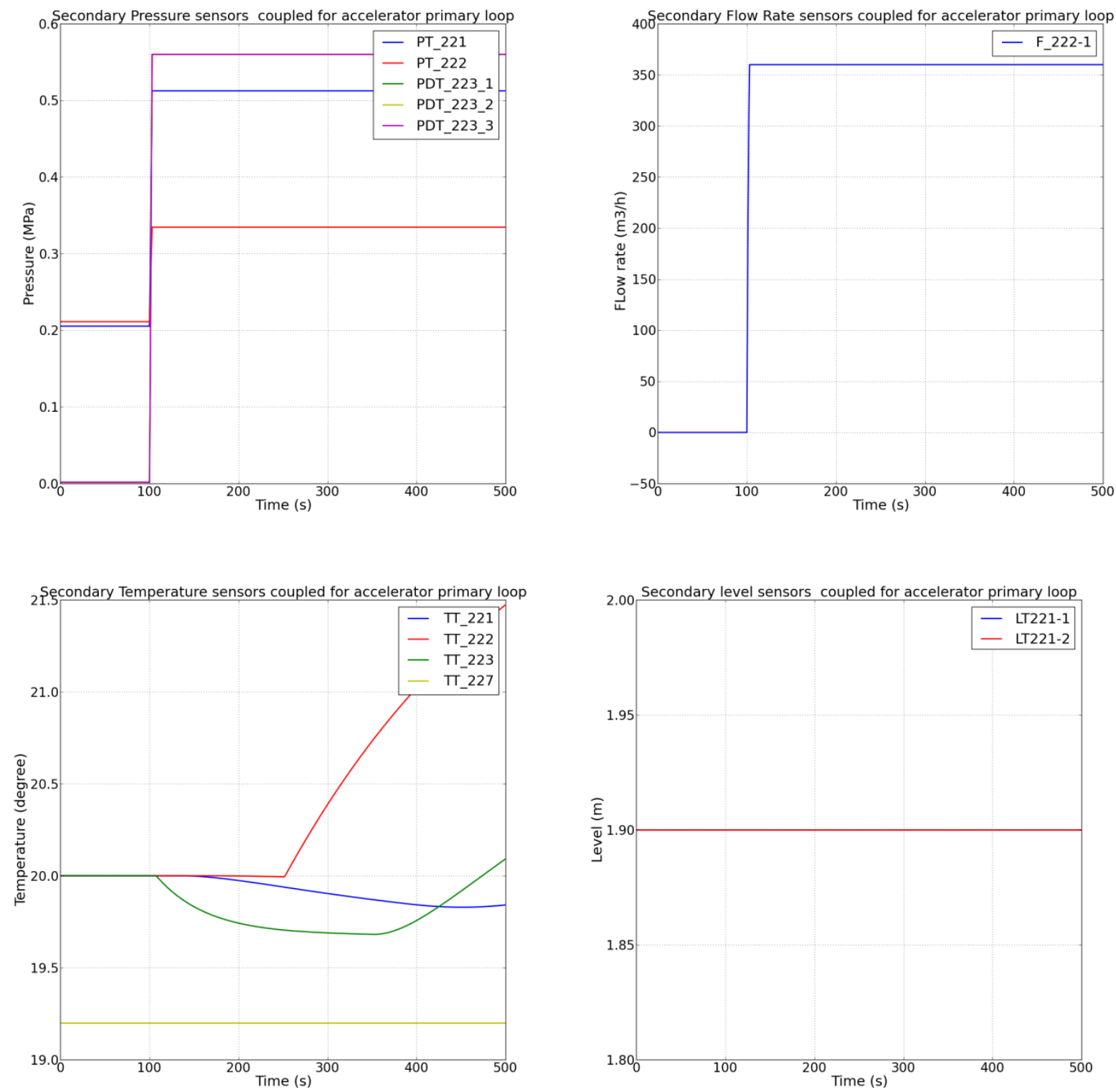

Figure 26. Calculated pressure, total flow rates, and temperatures of the secondary cooling loop coupled with the accelerator primary cooling loop and pump Z-202/1 and Z-202/2 operating at full speed and the KIPT neutron source facility starts from cold shutdown for 500 s operating time. 

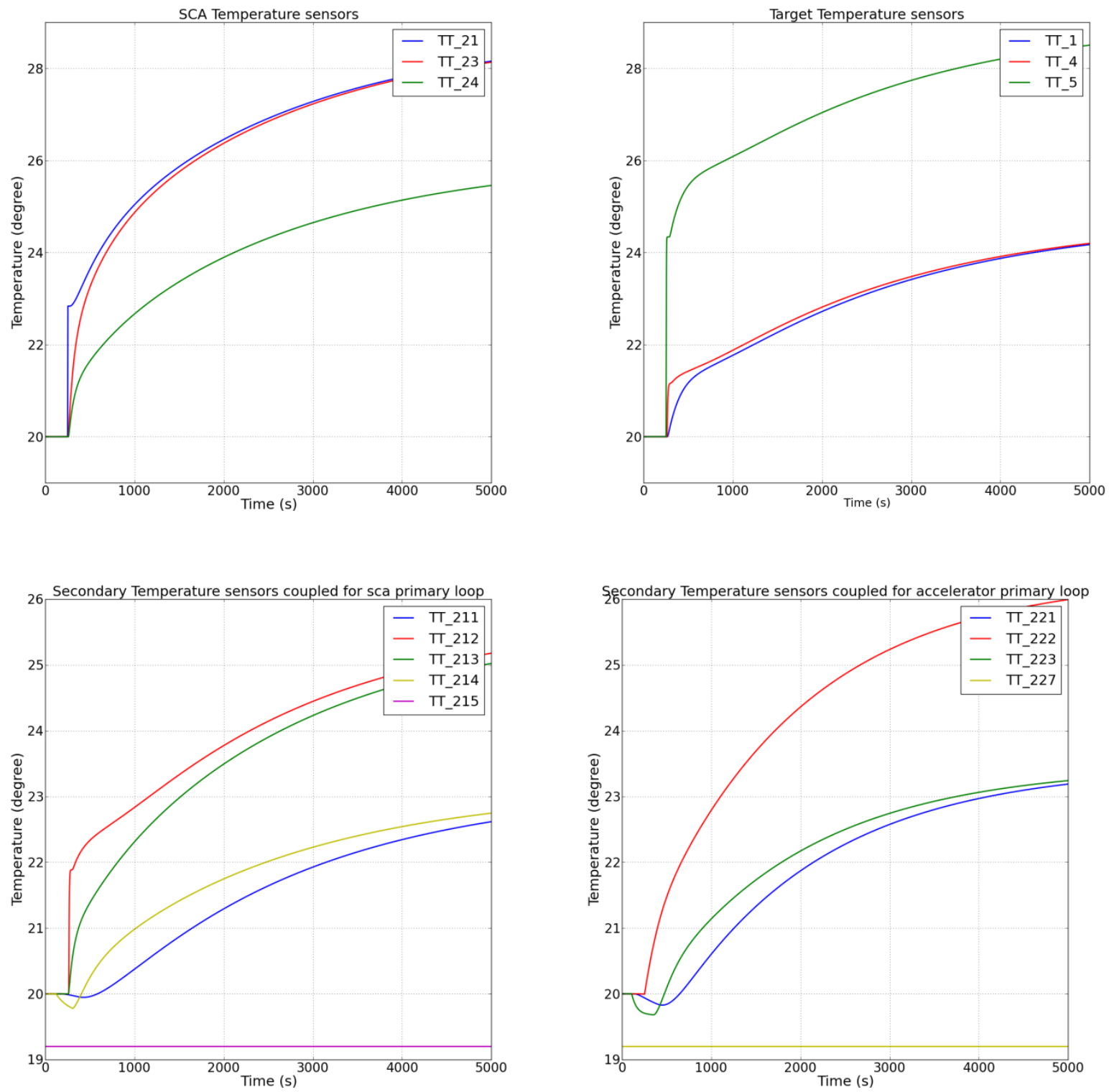

Figure 27. Calculated temperatures of the KIPT neutron source facility starting from cold shutdown for 5000 s operating time.

\section{Shutdown}

The sequence of shutting down the KIPT neutron source facility is the reverse of the system start-up sequence. To simulate the shutdown, it is assumed that the cooling systems are operating at normal operations. The following sequence is used: the accelerator is shutdown at $100 \mathrm{~S}$, the subcritical primary cooling pumps are turned off after another $100 \mathrm{~S}$, the target primary cooling pumps are turned off at $300 \mathrm{~s}$, and the secondary cooling pumps are turned off at $400 \mathrm{~s}$, and the air blowers for the cooling 
towers are turned off at 500s. These time intervals are selected arbitrary for this demonstration. For the actual facility shutdown, the operator has to wait till the coolant temperature in all the loops decrease to the cold shutdown conditions.

Figures 28 to 31 show the measured sensor values for the shutdown event based on the above time sequence. The pressure and the flow rates of each cooling loop decrease to the initial values as previously shown Figures 23 to 26 . The temperatures of the cooling water decrease as soon as the accelerator power is turned off. The coolant temperatures of each coolant loop stop decreasing as soon as its pump is turned off.
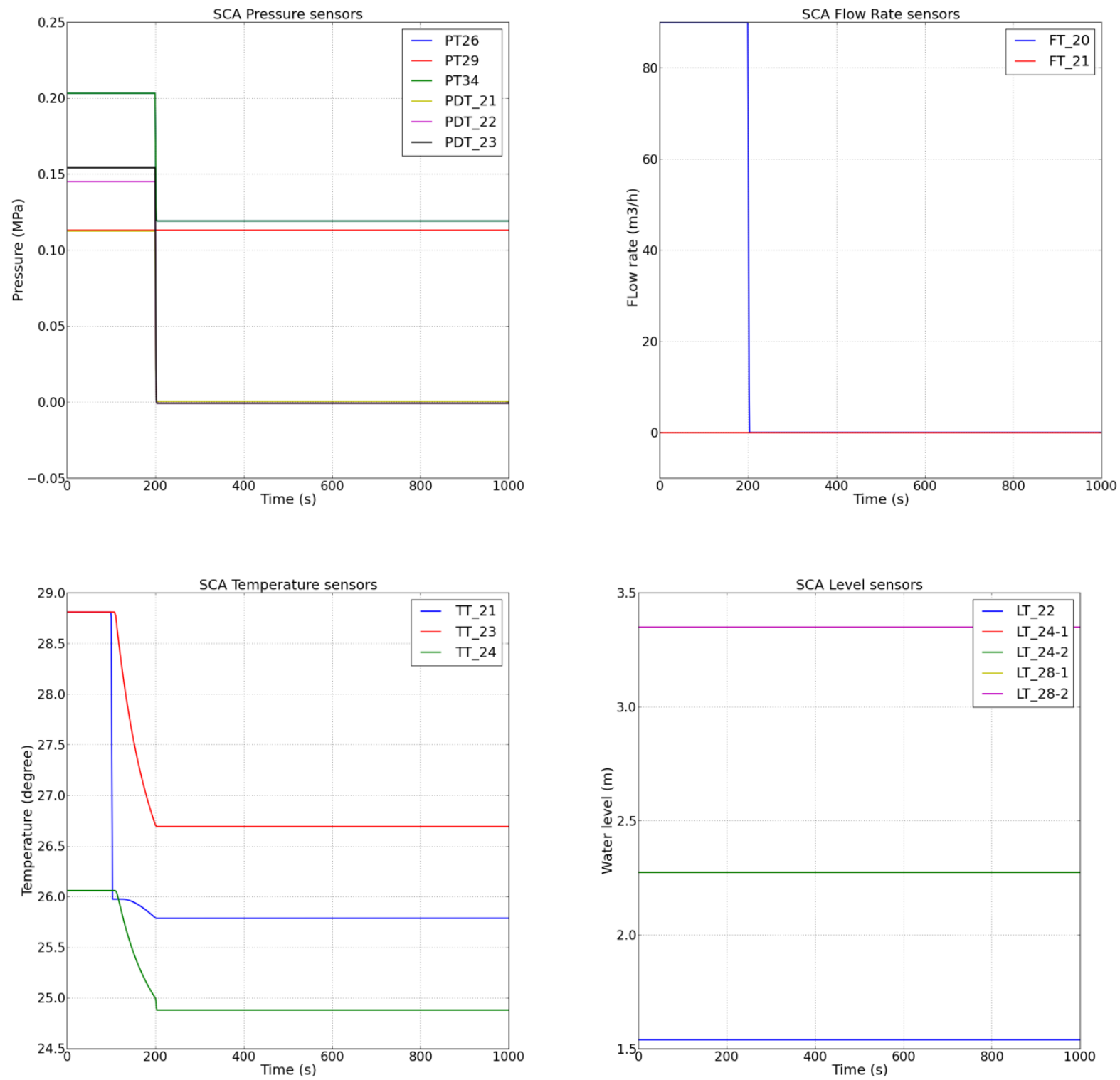

Figure 28. Calculated pressure, flow rates, and temperatures of the subcritical assembly primary cooling loop for the assumed shutdown test case. 

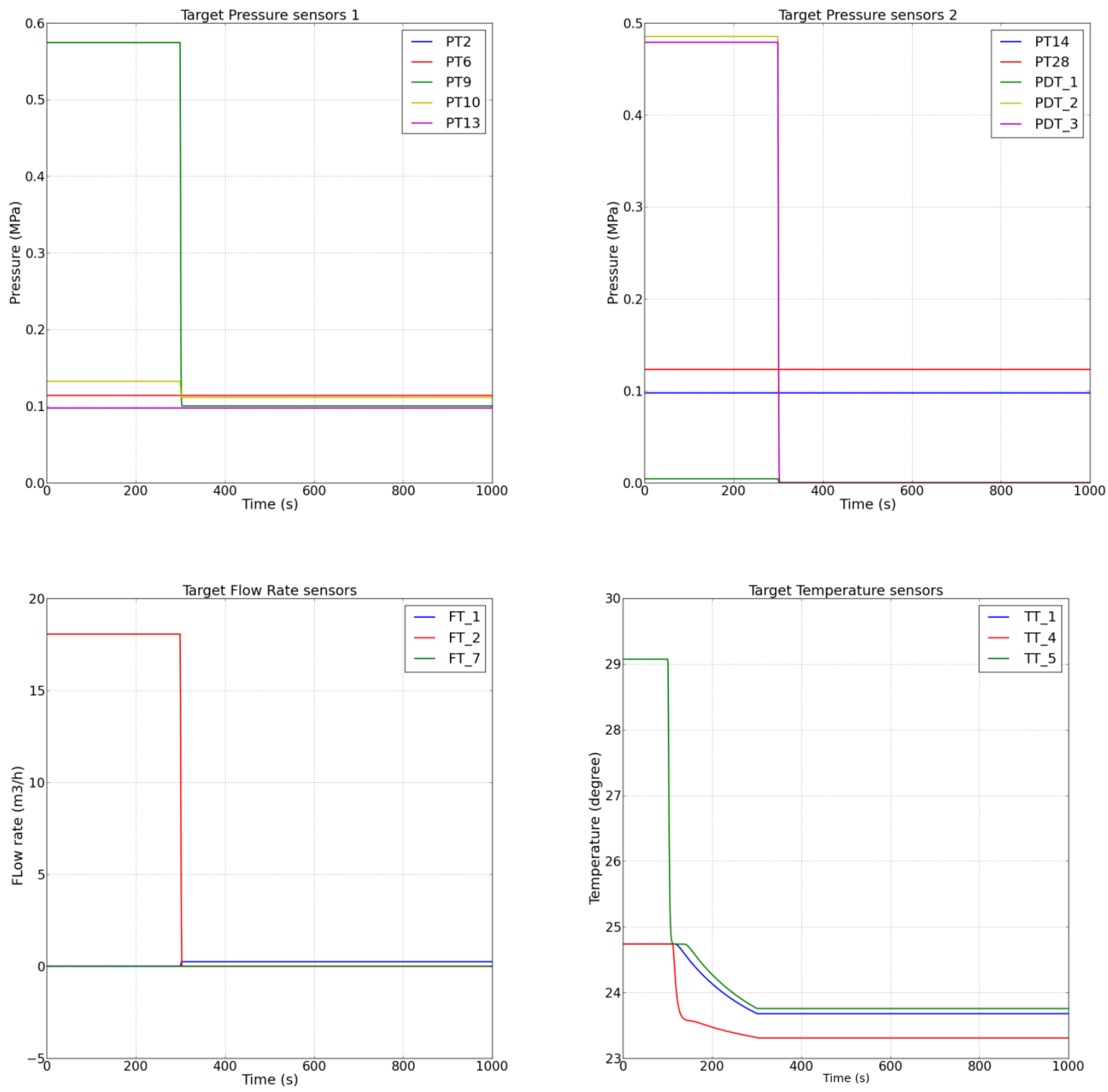

Figure 29. Calculated pressure, flow rates, and temperatures of the target primary cooling loop for the assumed shutdown test case. 

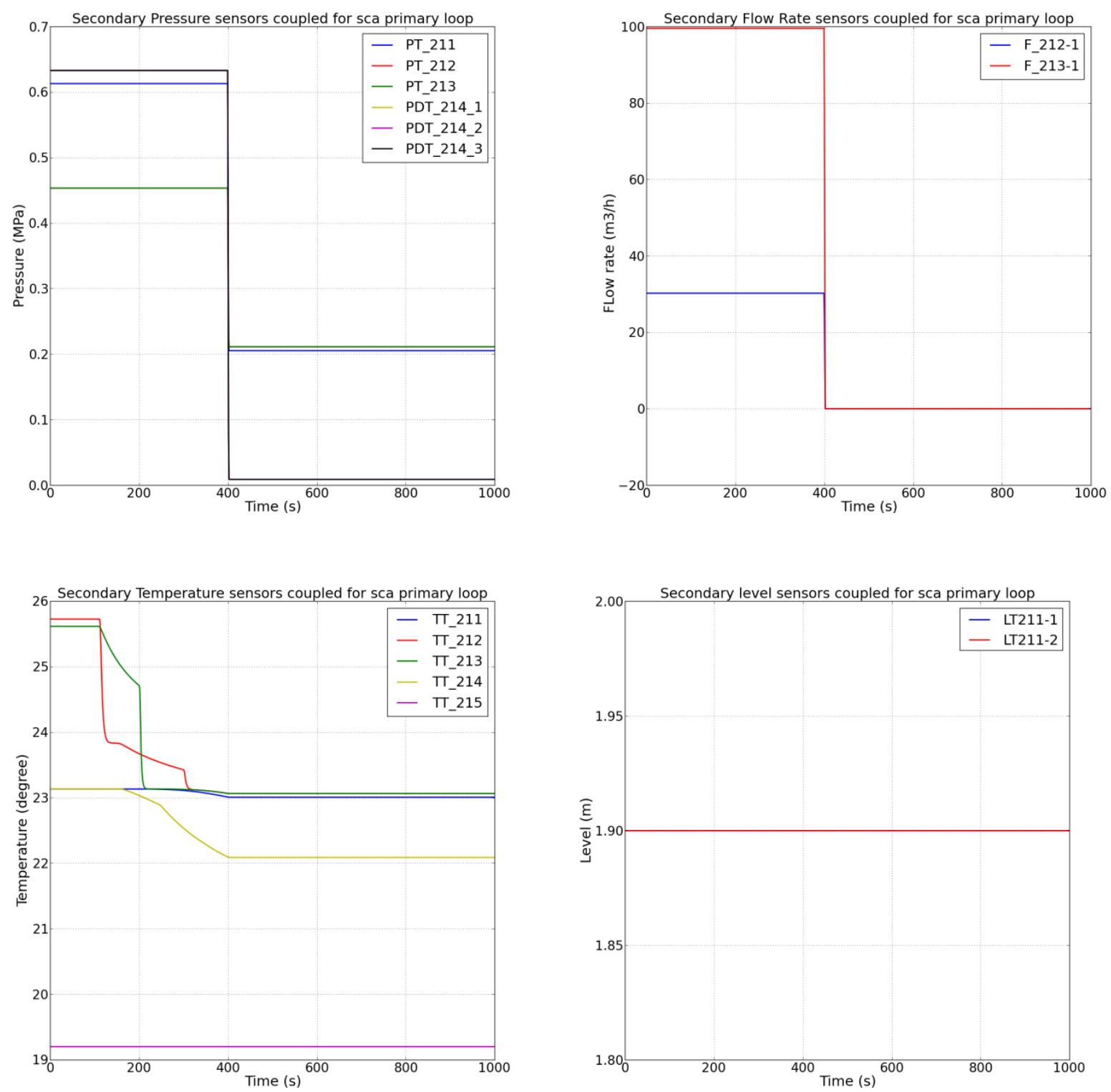

Figure 30. Calculated pressure, flow rates, and temperatures of the secondary cooling loop coupled with the target-subcritical assembly primary cooling loops for the assumed shutdown test case. 

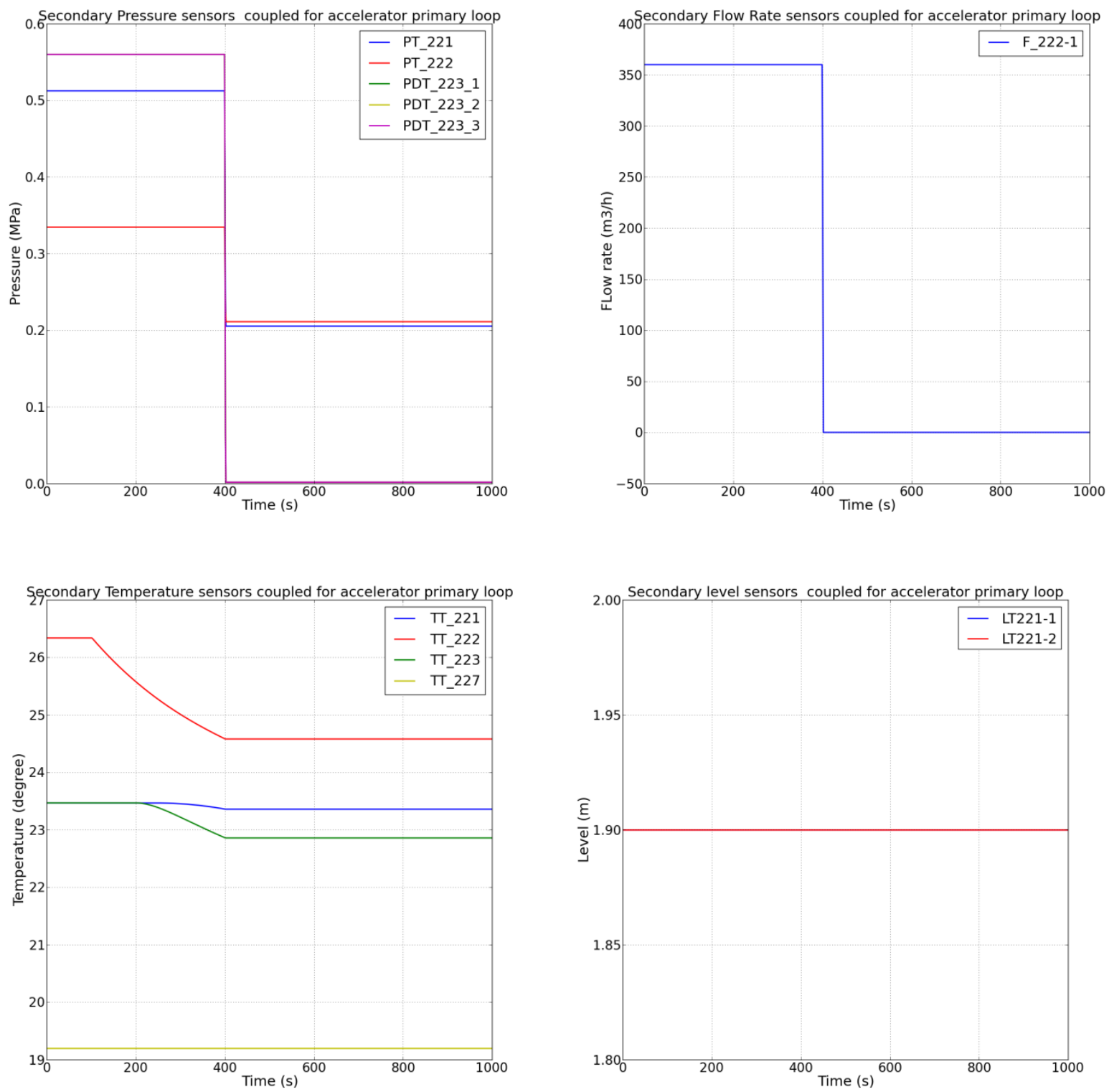

Figure 31. Calculated pressure, flow rates, and temperatures of the accelerator secondary cooling loop for the assumed shutdown test case.

\section{Component Failure Simulations}

In addition to normal simulation test cases, several component failure simulations were performed to demonstrate the capabilities of the plant model. These simulations are accelerator power trip, pump trip of the subcritical assembly primary loop, the target primary loop and the secondary coolant loop, and air blower trip of the secondary coolant loops. The results from these simulations are discussed in this section. 


\section{a) Accelerator power trip}

During the $1000 \mathrm{~s}$ interval considered in this simulation, the accelerator power is tripped with a trigger signal coming at $100 \mathrm{~s}$ during normal operation. All the other components are operated normally.
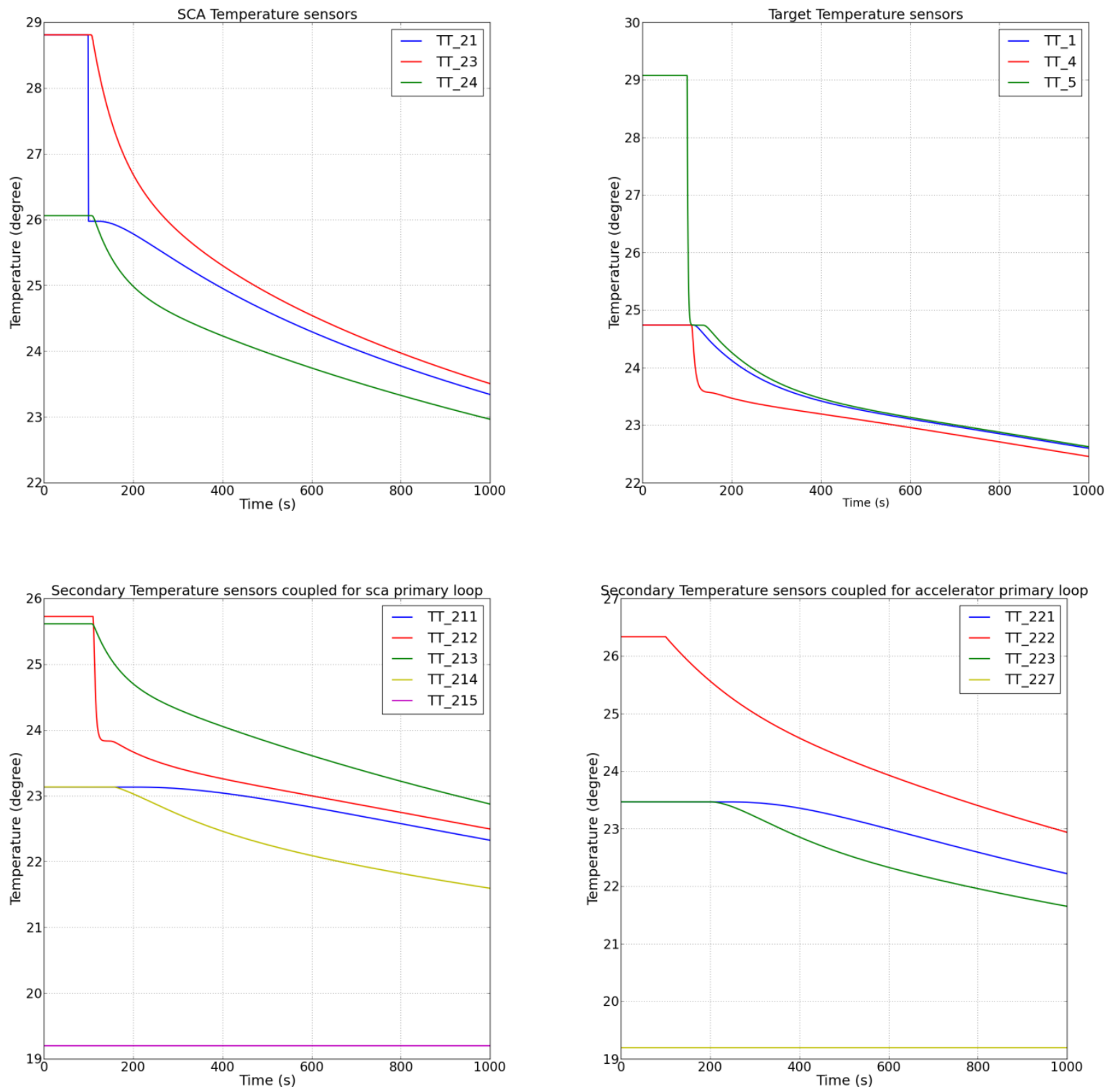

Figure 32 Calculated sensor temperatures of the KIPT neutron source facility for the accelerator trip event.

The simulation results show that all the pressures and flow rates in each of the cooling loops are the same as the initial steady state values in the null transient cases therefore they are not repeated in this report. Figure 32 shows the transients recorded by each temperature sensor for the four cooling loops due to the loss of accelerator beam power. 
They continuously drop after the accelerator power trip in the $1000 \mathrm{~s}$ simulation interval, because the coolant flow in the system keeps removing the residual heat in the system to the environment.

\section{b) Pump trip of the subcritical assembly-target secondary coolant loop}

The second test case is the trip of the main pump in the primary SCA cooling system. This test case starts from the normal steady state operation of the cooling systems. The transient is initiated by turning off the main pump $\mathrm{H} 22$ with a trigger signal at $10 \mathrm{~s}$. Other control components in the cooling systems remain at the normal operation status. For demonstration purpose, the $\mathrm{H} 22$ pump stops in about one minute.

All the pressure and flow rate sensors of the target primary cooling loop have the same value as the null transient case since no component positions have been changed during the transient in this cooling loop, as well as pressure and flow sensor values of the secondary cooling loops. Figure 33 shows the transients of the pressure sensor, the flow rate sensor, and the temperature sensors in the SCA primary cooling loop. Both the pressure and the flow rates are reduced as the pump speed falling. The temperature of the cooling water out of the SCA tank increases due to the reduced flow rate in the SCA primary system.

In the KIPT neutron source facility, the plant protection system will be automatically triggered if such an accident scenario occurs, i.e., the accelerator will be turned off while the temperatures of the coolant water inside the cooling systems deviated from the nominal values by a few percent. To simulate this scenario, in this test case, the beam power is turned off completely within 3 seconds while the temperature of the coolant water out from the SCA tank increased over $20 \%$ from the normal steady state operation.

At about $42 \mathrm{~s}$ as shown in Figure 33, the temperature value of TT_21 sensor decreases rapidly to the water temperature in the SCA water tank due to the shutdown of the accelerator power. The temperature at the inlet of the heat exchanger TT_23 increases slightly during the transition period due to the warmer water out of the SCA tank mixed with the water in tank E22. The temperature at the outlet of the heat exchanger (TT_24) decreases during the transition period due to the reduced flow rate in the primary side of the heat exchanger. The temperature transient stops when the flow rate in this cooling loop becomes zero.

Figure 33 also shows the temperature variations in the target primary loop within the first $500 \mathrm{~s}$. Figure 34 shows the temperature variations in the two secondary cooling loops. The temperatures at all of these loops decrease as the accelerator is turned off, and continue to fall within the $500 \mathrm{~s}$ interval since the flows in those loops do not stop and continue to remove the residual heat out of the cooling system.

An accident scenario with the main pump $\mathrm{H} 2$ of the target primary cooling loop tripped at $10 \mathrm{~s}$ is also simulated. Figure 35 shows the transients of the pressure sensors and flow sensors in the target primary cooling loop, which decreases due to the trip of the pump. 
Figure 36 shows the temperature variations in each of the cooling loop. In this test case, the accelerator is turned off after the temperature at the target outlet increased by more than $20 \%$ to simulate the plant protection mechanism in the KIPT neutron source facility. The temperatures in the SCA primary loop and the secondary cooling loops decrease gradually after the accelerator is turned off within the first 500 seconds, however, the temperatures in the target primary loop falls and stops while the flow rate in the loop was reduced to zero.

In another test case, the secondary cooling loop of the SCA and target primary loops is tripped at $10 \mathrm{~s}$ during steady state operation. The pressure and the flow rates in the SCA and target primary cooling loops are the same as in the null transient. Figure 37 shows the transients in the secondary cooling loop for the first $500 \mathrm{~s}$. The pressure and flow rates in the secondary cooling system gradually decrease as the secondary pumps are slowed down. The amount of heat removed from the primary loops is reduced to zero as the secondary pumps are stopped. The water temperature of the secondary cooling loop increases as the flow rate is decreased. This temperature increase is stopped as soon as the flow rate value is zero. The temperatures of the cooling water in the SCA and target primary loops increase since the heat removal to the secondary cooling loop is decreased as shown in Figure 38. The plant protection system turns off the accelerator as soon as the temperatures in the primary loops increased by more than $20 \%$. Consequently, the temperatures of the SCA, the target primary loop, and the secondary loop of the accelerator primary loop are decreased as shown in Figure 37 and Figure 38, except those of the secondary loop of the SCA and target primary loops because the flow rate value is Zero. 

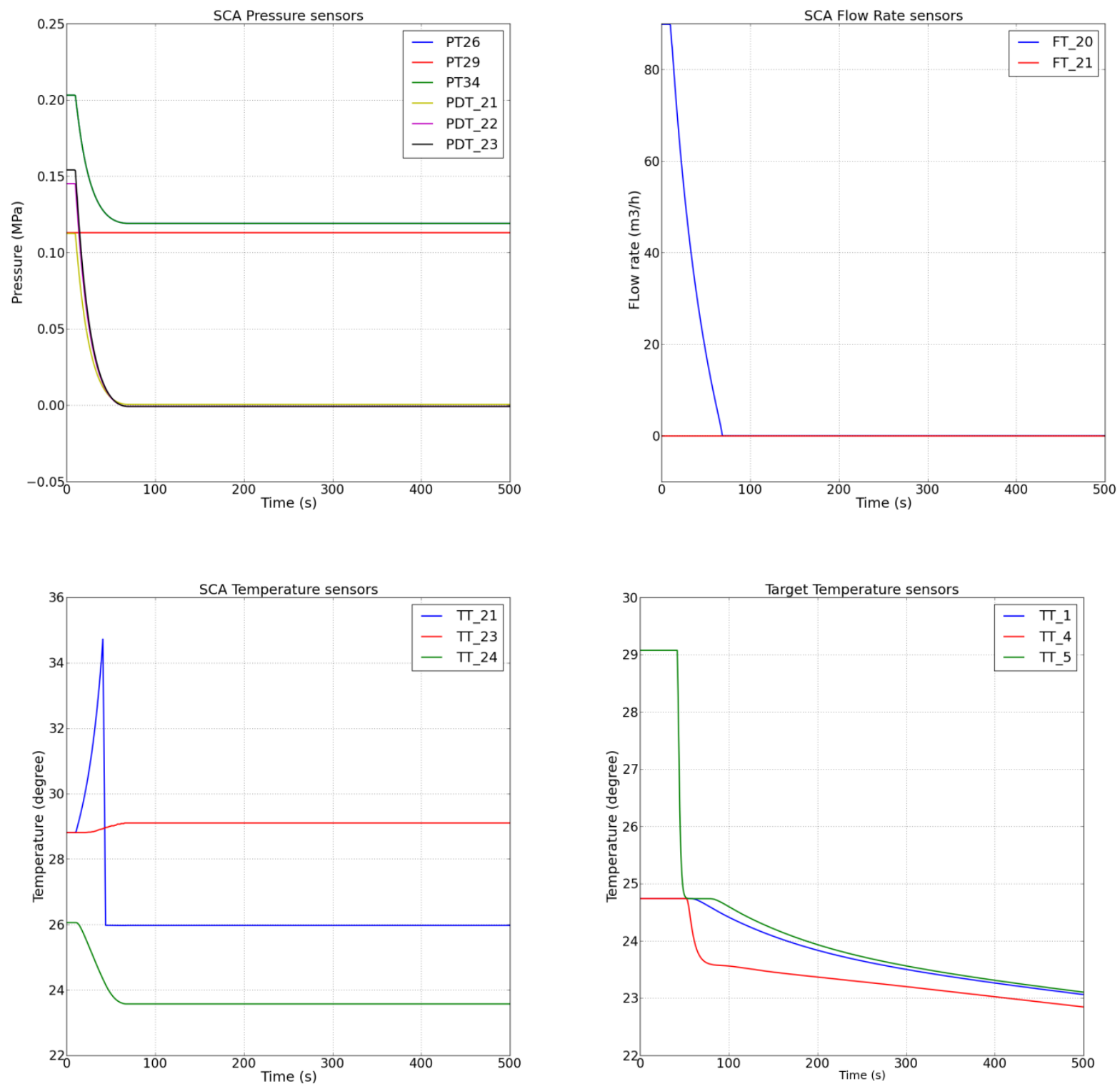

Figure 33. Calculated pressure, temperature, and flow rates in the SCA and the target primary loop of the KIPT neutron source facility for the SCA pump trip accident. 

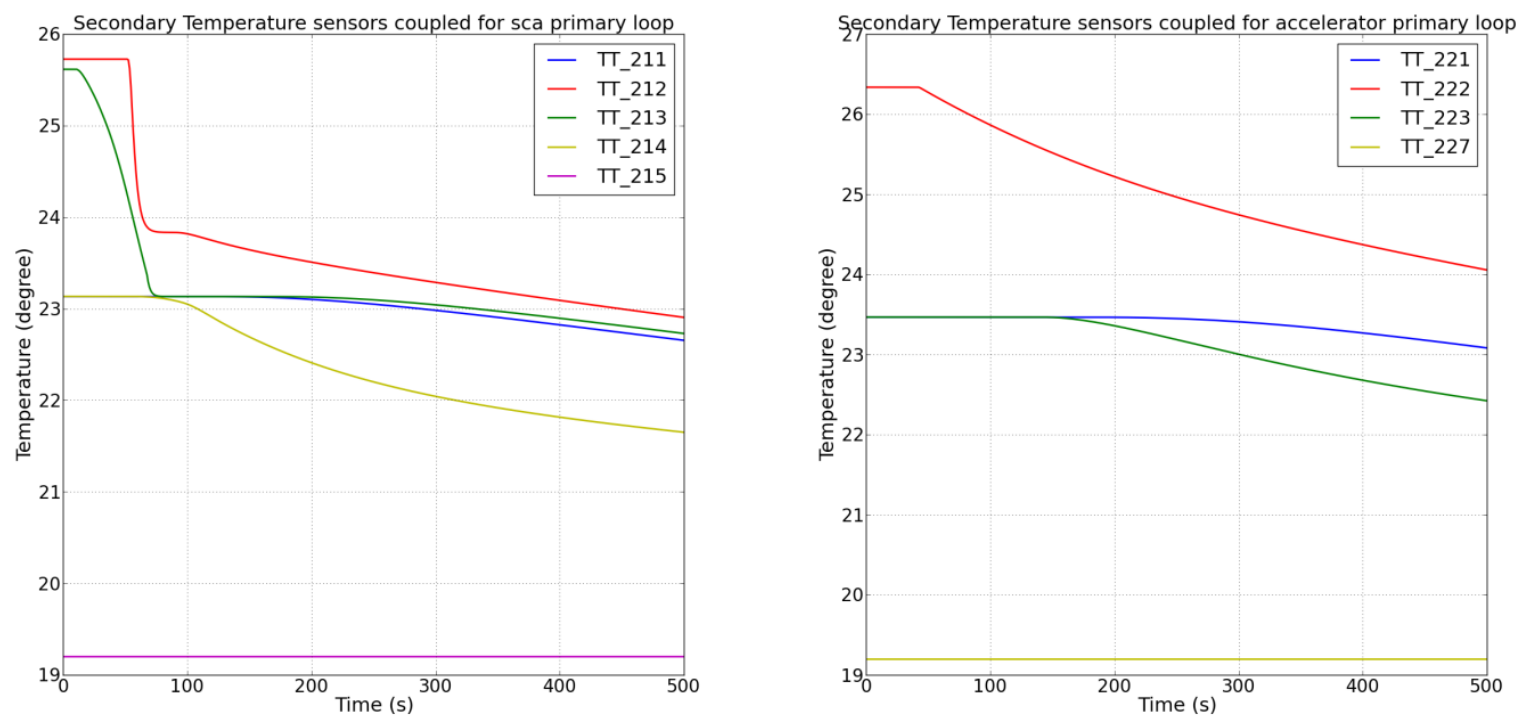

Figure 34 Calculated temperature in the secondary loops of the KIPT neutron source facility for the SCA pump trip accident. 

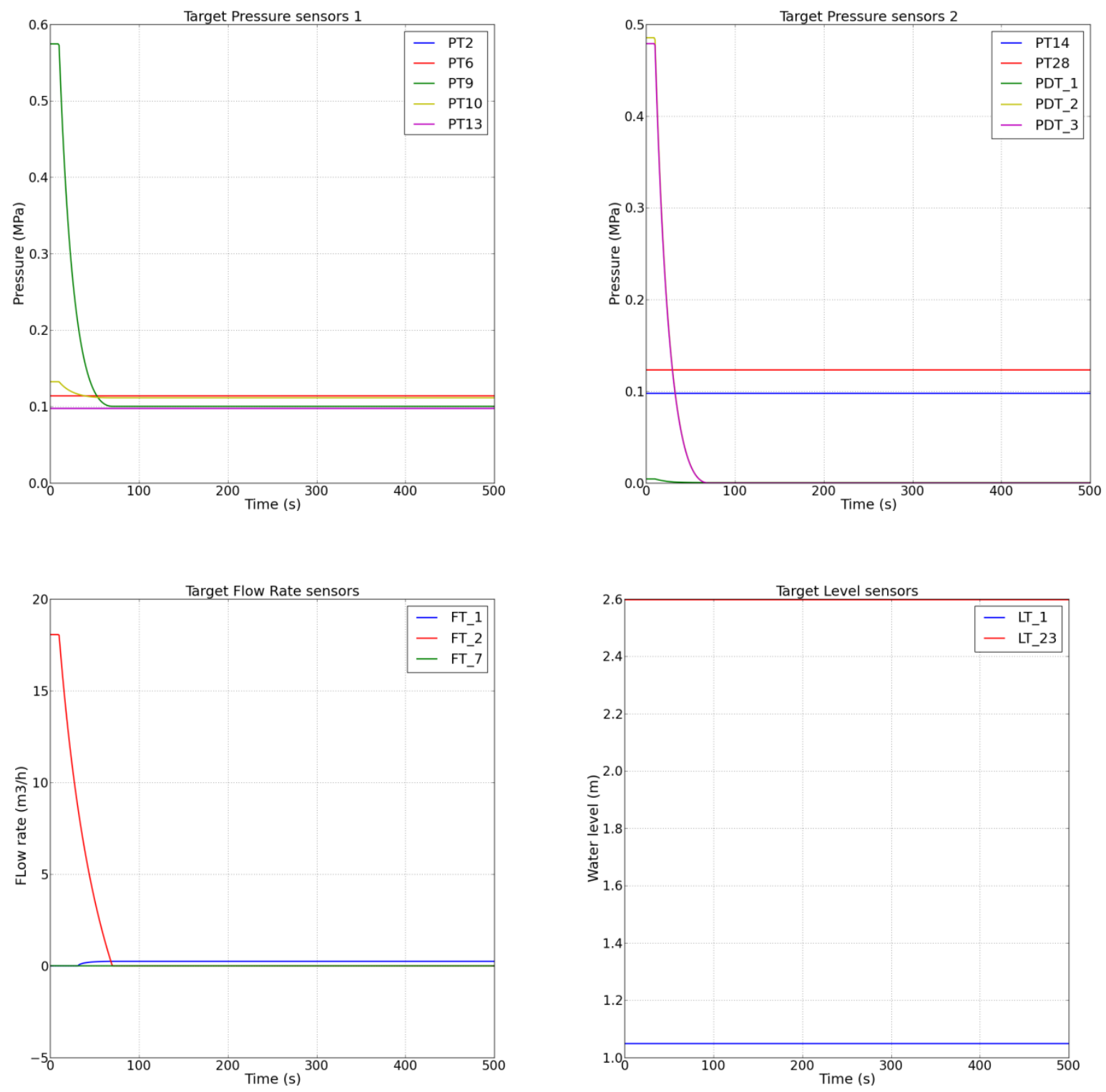

Figure 35. Calculated pressure, temperature, and flow rates in the target primary loop of the KIPT neutron source facility for the target pump trip accident scenario. 

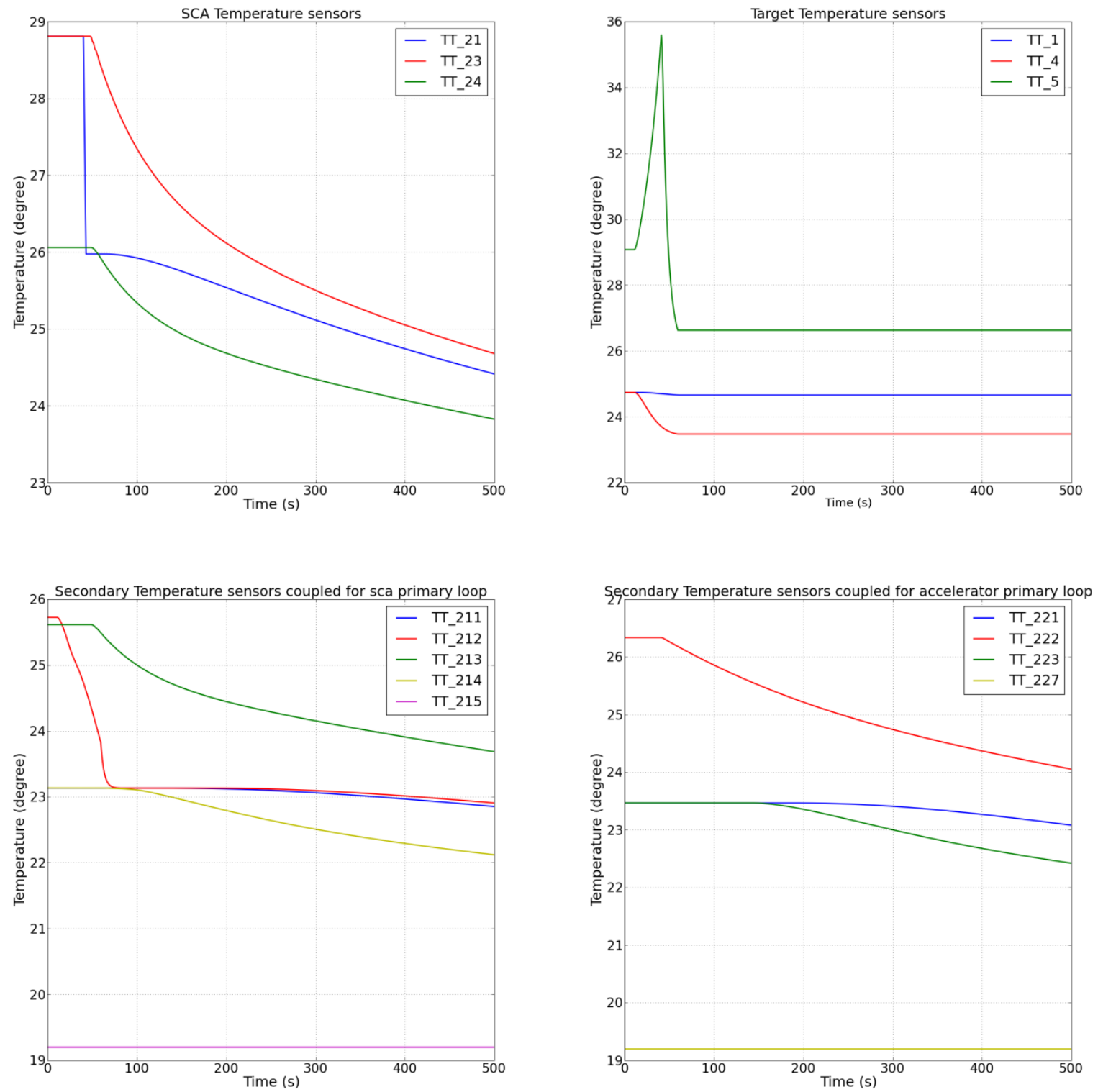

Figure 36. Calculated temperature in the cooling loops of the KIPT neutron source facility at the target pump trip accident scenario. 

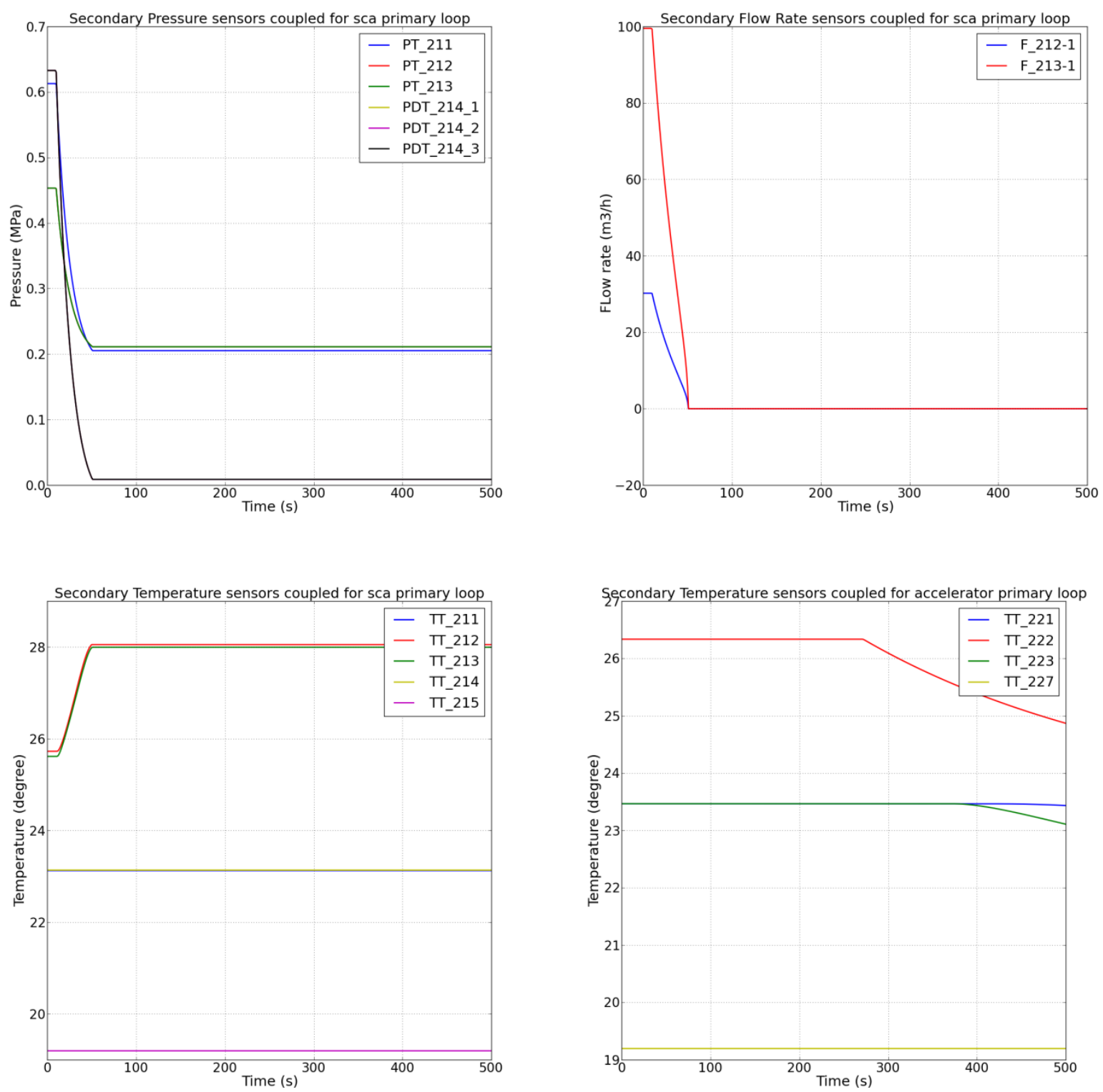

Figure 37. Calculated pressure, flow rates, and temperature in the secondary loop coupled with the primary loops of the KIPT neutron source facility for the secondary cooling system pump trip accident scenario. 

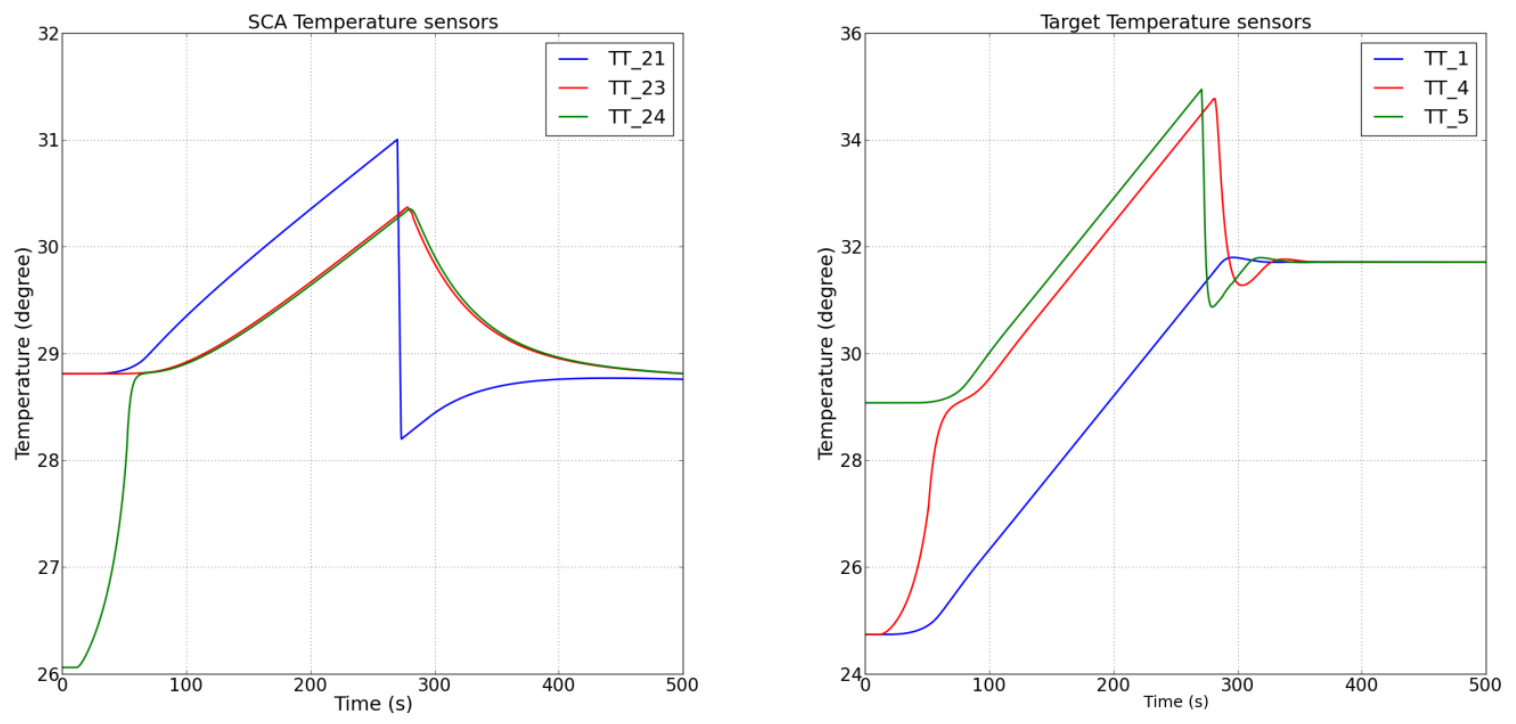

Figure 38. Calculated temperature in the SCA and target primary cooling loops of the KIPT neutron source facility for the secondary cooling system pump trip accident scenario.

\section{c) Air blower trip of the subcritical assembly-target secondary coolant loop}

The last test case simulates turning off the cooling tower air blowers of the secondary cooling loops at $10 \mathrm{~s}$. All the other system components remain at the normal operating conditions. The pressure and flow rates remain the same as in the previous null transient calculations. Figure 39 shows the temperature variations in the four system cooling loops within the first $5000 \mathrm{~s}$. With the air blower stopped, the heat cannot be removed to the ambient environment and the cooling water temperatures increase in all the loops. The plant protection system turns off the accelerator power when the temperature in the primary cooling increased by $20 \%$ from the normal value. The temperatures in all the cooling loops then decrease and converge to new values. 

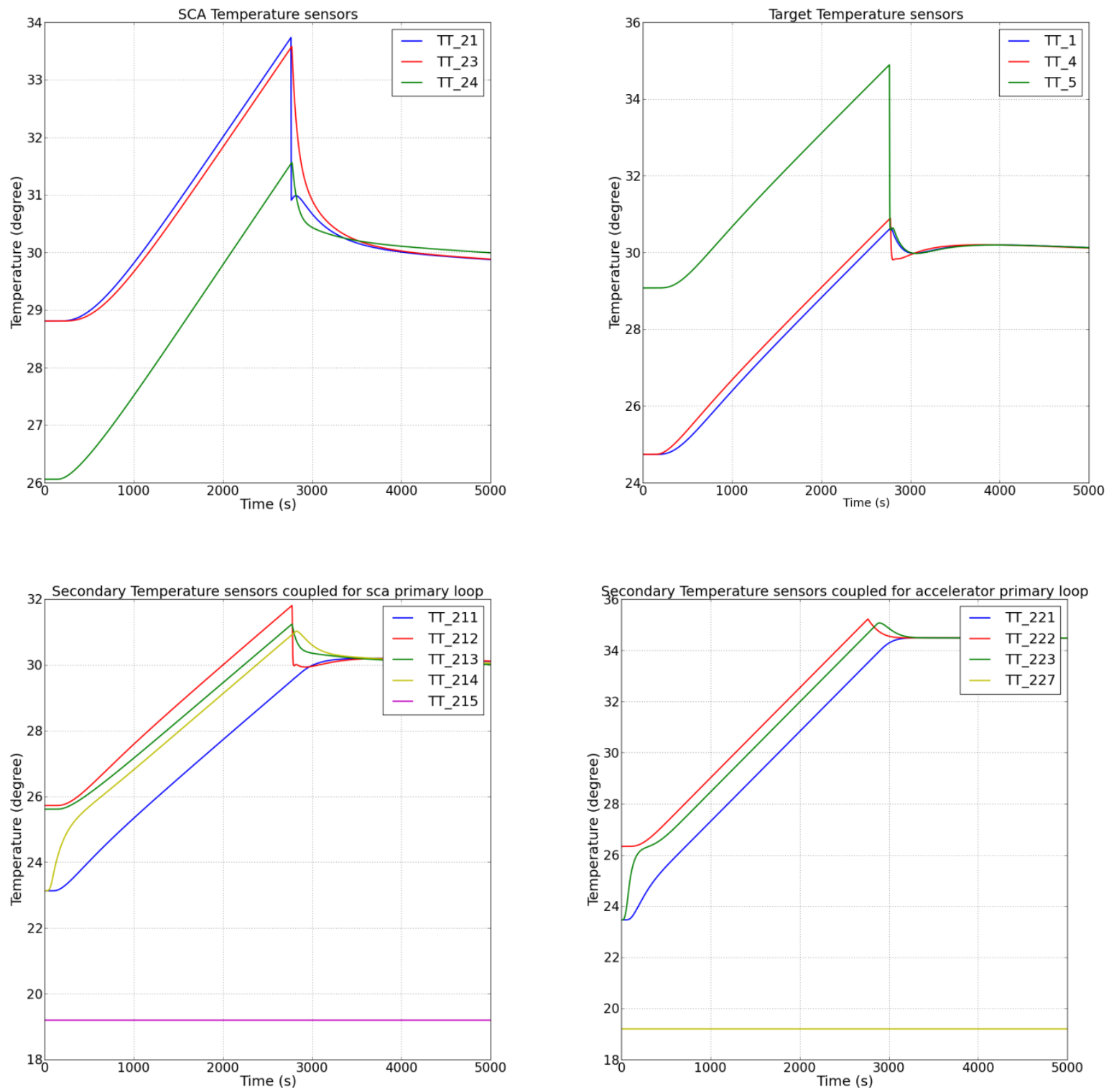

Figure 39. Calculated temperatures of the different cooling loops of the KIPT neutron source facility for the cooling tower air blower trip accident scenario.

\section{Summary}

A plant model of the KIPT neutron source facility was developed using the PYTHON script language. The model is used in the KIPT neutron source facility simulator for training the facility operators. The plant model simulates the neutron source facility during normal, startup, and shutdown operations, and during accident scenarios. This plant model has flexibility to use different initial conditions. The model can simulate the real-time responses of the different sensors for many combined transient scenarios. 


\section{References}

[1] Z. Zhao, Y. Gohar, D. G. Naberezhnev and J. Duo, "Shielding Analysis and Design of the KIPT Experiment Neutron Source Facility of Ukraine," ANL-08/23 (2008).

[2] Austin L. Grelle, Yan Cao, Yousry Gohar, Young Park, and Tom Wei, "Neutron Source Facility Simulator (NSFS)," Argonne National Laboratory Report, ANL14/07, March 2014.

[3] Y. Gohar, T. Wei, L. Briggs, Y. Park, T. Sumner, A. L. Grelle and S. J. Stein, "Control and Protection System Conceptual Design Logic Diagrams for Neutron Source Facility at Kharkov Institute of Physics and Technology," ANL-13/10, December 2013.

[4] "Experimental Physics and Industrial Control System," http://www.aps.anl.gov/epics/.

[5] G. van Rossum, "Python tutorial", Technical Report CS-R9526, Centrum voor Wiskunde en Informatica (CWI), Amsterdam, May 1995.

[6] P. Stabat and D. Marchio, "Simplified Model for Indirect-Contact Evaporative Cooling-Tower Behaviour," Applied Energy, 78, 433-451 (2004). 


\section{Appendix A: Component Control Functions}

\section{a) Pump}

During the operation, the pump speed varies from zero to the maximum full speed. In the physical model described in Section II, the pump speed $\mathrm{S}$ is selected as the control factor, with its value varies in the range of 0 to 1 . This variation is modeled with a characteristic shape function $1 /\left(1+\frac{t}{\tau}\right)$, where $\tau$ is the time characterizing the pump transition, i.e., in this model, $\tau$ simply is the time for the pump speed to change from speed- $S_{1}$ to speed $S_{2}$. Therefore, the pump control function can be expressed as:

$$
\begin{gathered}
\mathrm{S}(\mathrm{t})=\mathrm{S}_{1}+\left(\mathrm{S}_{2}-S_{1}\right) \times f\left(t-t_{\text {sig }}\right), \\
\left\{\begin{array}{cc}
\text { if }\left(t-t_{\text {sig }}\right) \leq \tau: & f\left(t-t_{\text {sig }}\right)=2 \times\left(1-\frac{1}{1+\frac{\left(t-t_{\text {sig }}\right)}{\tau}}\right) \\
\text { else }: & f\left(t-t_{\text {sig }}\right)=1.0
\end{array}\right.
\end{gathered}
$$

Where $t_{s i g}$ is the time trigger signal passed from EPICS to represent the time when the component status changes.

\section{b) Accelerator power}

The control of the accelerator power in the plant model is similar to the control of the pump, except that a linear function is directly applied to the control function as follows:

$$
\begin{gathered}
E(\mathrm{t})=\mathrm{E}_{1}+\left(\mathrm{E}_{2}-E_{1}\right) \times f\left(t-t_{\text {sig }}\right), \\
\left\{\begin{array}{cc}
i f\left(t-t_{\text {sig }}\right) \leq \tau: & f\left(t-t_{\text {sig }}\right)=\frac{\left(t-t_{\text {sig }}\right)}{\tau}, \\
\text { else }: & f\left(t-t_{\text {sig }}\right)=1.0
\end{array}\right.
\end{gathered}
$$

Where, $E_{1}$ and $E_{2}$ are the old and new power level in the system, and $t_{\text {sig }}$ is the time trigger signal passed from EPICS to represent when the accelerator power changes.

\section{c) Block Valves}

The block valves are only modeled to have two positions "open" or "closed" in this simulator. To switch between the two states, a transient period is modeled using an exponential function to adjust the resistance " $\mathrm{K}$ " of that valve. During the transient time, a factor $f$ is applied to the original resistance of the segment and is calculated based on the final position status "open" or "closed." 


$$
\left\{\begin{array}{cl}
\text { if open: } & k=\left\{\begin{array}{cc}
K_{e} \times e^{-\frac{\left(t-t_{\text {sig }}\right)}{\tau} \ln K_{e}} & t-t_{\text {sig }} \leq \tau \\
1.0 & t-t_{\text {sig }}>\tau
\end{array}\right. \\
\text { if closed: } & k=\left\{\begin{array}{cc}
e^{\frac{\left(t-t_{\text {sig }}\right)}{\tau} \ln K_{e}} & t-t_{\text {sig }} \leq \tau \\
K_{e} & t-t_{\text {sig }}>\tau
\end{array}\right.
\end{array}\right.
$$

Where $K_{e}$ is the resistance of a valve when it is closed, and is chosen to be about $10^{6}$ as discussed previously in Section II. Again, $t_{\text {sig }}$ is the time trigger signal passed from EPICS, when the valve status changes.

\section{d) Air Blower}

The air blowers of the cooling towers are similar to the block valves. There are only two positions "on" or "off" in the model, however, a transition function is provided to simulate the transient period. For the air blowers, a factor $f$ is calculated to adjust the air flow rates through the cooling towers, and it is expressed as a linear function as follows:

$$
\left\{\begin{array}{cl}
\text { if open: } & f=\left\{\begin{array}{cl}
\frac{\left(t-t_{\text {sig }}\right)}{\tau} & t-t_{\text {sig }} \leq \tau \\
1.0 & t-t_{\text {sig }}>\tau
\end{array}\right. \\
\text { if closed: } & f=\left\{\begin{array}{cl}
1.0-\frac{\left(t-t_{\text {sig }}\right)}{\tau} & t-t_{\text {sig }} \leq \tau \\
0.0 & t-t_{\text {sig }}>\tau
\end{array}\right.
\end{array}\right.
$$




\section{Argonne}

Nuclear Engineering Division

Argonne National Laboratory

9700 South Cass Avenue, Bldg. 208

Argonne, IL 60439

www.anl.gov 